\title{
Effect of Elevated Temperature on Axially and Eccentrically Loaded Columns Containing Polyvinyl Alcohol (PVA) fibers
}

\author{
Mohamed Said ${ }^{1}$, \\ Ahmed Abd El-Azim A. ${ }^{2}$, Mahmoud Ali M. ${ }^{2}$, Hany El-Ghazaly ${ }^{2}$, Ibrahim Shaaban ${ }^{3}$
}

\begin{abstract}
Polyvinyl Alcohol (PVA) fiber was developed more than 80 years ago in Japan. They are heavily used in non-structural applications and in Engineered Cementitious Composites (ECC) mainly for beams and thin slabs sections. There are gaps in the research regarding their performance in other structural elements and at elevated temperatures. The aim of this work is to study the behavior of reinforced concrete columns containing PVA fibers after being subjected to elevated temperatures and then loaded either concentrically or eccentrically. A total of thirty-six reinforced concrete columns, having constant longitudinal reinforcement, were experimentally tested under different load eccentricity ratios $(0.0,0.50$, and 1.0$)$. Different ratios of PVA, $0.75 \%, 1.50 \%, 2.25 \%$ were included in the concrete mixes. The studied columns were exposed to elevated temperature before loading. It was observed that columns containing PVA fibers had higher ultimate loads, higher ultimate deflection, less crack widths, higher ultimate deflection, higher energy absorption, and higher temperature resistance compared to normal reinforced concrete columns. In addition, these columns didn't show any sign of spalling due to the fiber bridging effect of PVA fibers unlike other studied normal reinforced concrete columns without fibers. It was found that addition of $1.50 \%$ fiber content showed better performance for centrically loaded columns while this was raised to be $2.25 \%$ for eccentrically loaded columns. The ultimate load of the columns exposed to elevated temperature rapidly decreased with increasing the duration of temperature to different magnitudes depending on the percentage inclusion of PVA fibers. It was found that ductility and energy absorption for columns including 1.5\% PVA were higher than their companions without fibers after temperature exposure. It was observed that the energy absorption of eccentric columns exposed to temperature for up to two hours was still higher than that of their companions without fibers by $40 \%$ for eccentricity ratio of 1.0 .
\end{abstract}

\section{Keywords}

Polyvinyl Alcohol (PVA) fibers; overheating; columns; eccentricity; energy absorption; ductility; ultimate load; ultimate deflection

\section{Introduction}

\subsection{Effect of PVA on Cement Composites}

Polyvinyl alcohol was a synthetic colloid prepared by Herrmann and Haehnel in the year 1924 (Thong et al., 2016). Dr. Sakurada's at Kyoto Imperial University in Japan developed polyvinyl alcohol fiber in 1939 (Horikoshi et al., 2006). This organic synthetic fiber has many advantages compared to other fibers including ductility, resistance to corrosion and the alkaline environment in concrete, strong bonding with the cement matrix, low cost and control of cracking over the long term. It has been used in many nonstructural applications including: recycled aggregate surface pretreatment (Kou and Poon, 2010), fiber-cement roofing as asbestos replacement, tunnel lining, industrial floors, pavement overlays and various kinds of shotcrete, however, it has gained wide attention when used in Engineered Cementitious Composites (ECC), (Horikoshi et al., 2006). Several researchers reported the superior properties of PVA fibers either in fiber reinforced concrete

1- Civil Engineering Department, Faculty of Engineering, Shoubra, Benha University

2- Civil Engineering Department, Faculty of Engineering, Fayoum University

3- Civil Engineering and Built Environment, School of Computing and Engineering, University of West London 
or in Engineered cementitious composite (ECC), which has outstanding tensile strain hardening behavior (Noushini et al., 2014; Meng et al., 2017). In addition, extensive investigations have been conducted to study the effect of PVA on key mechanical properties of concrete.

Hamoush et al., (2010) tested the stress strain behavior in tension and compression for samples with PVA. They reported that PVA fibers delayed the development of microcracks and the composite demonstrated greater strength and crack resistance than a similar matrix of plain concrete. Moreover, the failure mechanism of the specimens subject to axial compression exhibited no strain-softening response and the descending branch after peak stress was almost vertical. Adding PVA fibers to a plain concrete matrix had little effect on its precracking behavior but substantially enhanced the post-cracking response, which lead to improved ductility and toughness. Noushini et al. (2013), studied the effect of PVA fibers on the static 28 days mechanical properties along with the dynamic fundamental frequency, modulus of elasticity and damping ratio. They reported that the static properties were enhanced, but due to the low volume of fibers included in their samples, the dynamic behavior was not affected. Noushini et al. (2015) tested $1900 \times 150 \times 200 \mathrm{~mm}$ beams with PVA fibers by four-point static flexural, three-point cyclic and impact resonant frequency tests. The samples had a maximum compressive strength of $67 \mathrm{MPa}$. They reported that PVA fibre inclusion improved the ductility and damping ratio of the elements. In addition, PVA-FRC beams showed higher stiffness degradation rate and higher capacity to maintain their stiffness during testing.

Said et al., (2015) tested $590 \mathrm{~mm}$ X $220 \mathrm{~mm} \mathrm{X} 25 \mathrm{~mm}$ slabs with PVA fibers for toughness, compressive and flexural strength. They reported that the properties of the slabs were mainly dependent on the Reinforcing Index, which is the product of the PVA fiber volume percentage and fiber aspect ratio. Feng et al. (2018) concluded that steel fibers have a more positive effect on the impact strength of concrete, but samples with both steel and PVA fibers demonstrate even higher failure impact energy. Similar findings were reported by Nehdi and Ali (2019) who found that samples with hybrid PVA and shape memory alloy (SMA) resulted in superior impact resistance compared to that of control sample with PVA fibers only. Jang et al. (2014) subjected 55MPa concrete samples with and without $0.1 \%$ PVA to freezing and thawing cycles and then tested these samples for fatigue. They reported that PVA fiber inclusion enhanced both the flexural fatigue strength of concrete and resistance to freezing and thawing cycles. Similar findings on the freeze thaw resistance of concrete with PVA were reported by Wang and Li (2006). They also noted that although drying shrinkage of PVA-ECC (60 MPa) is higher than structural concrete due to high binder content, the cracking behaviour under restrained shrinkage is much better than that for concrete without PVA due to strain-hardening. Xu et al. (2018) tested $80 \mathrm{MPa}$ slender column samples having $0,0.25,0.5$ and $1 \%$ PVA fibers for compressive strength and creep. They reported limited effect on the compressive strength, but the creep property was significantly increased especially at higher PVA contents.

\subsection{Effect of elevated temperatures on specimens including PVA fibers}

Magalhães et al. (2013) showed that although melting of PVA fibers starts at $200^{\circ} \mathrm{C}$, at $145^{\circ} \mathrm{C}$ there is loss in stiffness and strength of the fibers is in the range of $14-17 \%$. At $220^{\circ} \mathrm{C}$, however, the elastic modulus and strength are reduced to approximately $55 \%$ and $48 \%$ respectively. Thermal analysis of PVA fiber showed that complete mass loss does not occur before $800^{\circ} \mathrm{C}$. Şahmaran et al. (2011) studied the effect of fly ash and PVA fibers on residual properties of engineered cementitious composites (strength 50-65 MPa), exposed to temperatures up to $800^{\circ} \mathrm{C}$. They concluded that spalling was observed for tested cubes without PVA fibers when subject to $400^{\circ} \mathrm{C}$ temperature for one hour. However, fiber melting guarded against spalling in the mixes with fibers in similar conditions. Özbay et al. (2015) compared the compressive strength, modulus of rapture and the bond characteristics of fiber reinforced concretes (steel, polypropylene and PVA) with that of nonfiber concrete after exposure to $400^{\circ} \mathrm{C}$. They reported that these properties were less affected by elevated temperature in steel fiber reinforced concrete compared with the plain concrete or that containing the other fibers. 
Pourfalah (2018) conducted tests on $50 \mathrm{MPa}$ concrete samples having PVA fibers only or hybrid PVA and Steel fibers. His samples were dog-bone shaped for direct tensile test (having a total length of $330 \mathrm{~mm}$ ), $50 \mathrm{~mm}$ cubes for compressive strength test and $170 \mathrm{~mm} \mathrm{X} 40 \mathrm{~mm} \mathrm{X} 20 \mathrm{~mm}$ prisms that were tested under four point bending. The samples were tested under room temperature or inside a heating chamber in which the samples were exposed to up to $600^{\circ} \mathrm{C}$. He reported that PVA samples lost 14 and $25 \%$ compressive strength when tested at $400{ }^{\circ} \mathrm{C}$ and $600{ }^{\circ} \mathrm{C}$, respectively. The inclusion of steel fibers, in the hybrid fiber samples reduced mass loss from the samples at $600^{\circ} \mathrm{C}$. $\mathrm{He}$ also noted that after exposure to temperatures beyond $150^{\circ} \mathrm{C}$ (near the melting point of the fibers), the failure mode of samples with PVA fibres changed from rupture to pulling out resulting in the change of behaviour of samples from deflection hardening to deflection-softening behavior. In another investigation, Cao, et al. (2019) compared the residual mechanical properties for high strength samples (> 85MPa), containing PVA or Carbon fibers or both after exposure to $800^{\circ} \mathrm{C}$ for up to 260 minutes. They concluded that the inclusion of the PVA in the samples can enhance the flexural strength and splitting strength of the concrete, but has little influence on the axial compressive strength when exposed to elevated temperatures. Both of the above investigations used small scale samples in the tests (cubes and cylinders).

\subsection{Concentric and Eccentric columns containing PVA fibers or ECC}

Pan et al., (2015) presented a theoretical models to predict column capacity under eccentric loading when PVA is included in the mix. Their models show good consistency with the simulated results, indicating that the proposed models are feasible and reliable for design. Yeganeh, and Anwar (2016) conducted an experimental and analytical investigation on axially loaded long and short columns containing PVA. Their mixes were ultra-high strength (136 MPa at 28 days). Nozawa et al. (2017) also conducted tests on cyclic loaded columns with compressive strength exceeding 140 $\mathrm{MPa}$ with PVA fibers. In addition to standard test samples for compressive and flexural strength testing, Li et al. (2016) prepared $250 \mathrm{~mm}$ X $250 \mathrm{~mm}$ X $1000 \mathrm{~mm}$ columns, which they coated with ultra-high toughness cementitious composites (UHTCC) containing $\mathrm{Nano}-\mathrm{SiO}_{2}$ and hybrid fiber combination of both steel and PVA. Their samples had an original compressive strength of $70 \mathrm{MPa}$ at room temperature and they reported the deterioration due to temperature exposure in the standard laboratory test samples. The columns coated with UHTCC were tested axially after temperature exposure to assess the effectiveness of the coating in protecting the columns from degradation due to high temperatures. Zhang and Deng (2018) conducted tests on $300 \mathrm{~mm}$ diameter X $1300 \mathrm{~mm}$ height columns reinforced with GFRP and containing PVA fibers under concentric loading. Their investigation was mainly concerned with the effect of reinforcement configuration on the columns behaviour.

Al-Gemeel and Zhuge (2018) investigated a strengthening system composed of a combination of basalt fibre textile with ECC to confine square concrete columns. Their results revealed that the new strengthening system has significantly enhanced the load carrying capacity and ductility of square concrete columns compared to the unconfined specimens and the specimens confined with textile reinforced mortars (TRM). Their results also showed that ECC itself could be used as a new retrofitting material in column confinement. Caie et al. $(2018$, a) carried out an experimental study on the mechanical behaviour of ECC-encased concrete filled steel tube (CFST) columns under axial loading. They tested six specimens, including four ECC encased CFST columns and two concrete-encased CFST columns. They found that ECC encased CFST columns showed both higher loading carrying capacity and more ductile behaviour. They developed a new method to calculate the carrying capacity of ECC-encased CFST columns and they verified it with experimental results. Cai et al. $(2018$, b) studied also the mechanical behavior of ECC-encased concrete filled steel tube (CFST) under eccentric loading. Their results showed that their proposed composite column exhibited both superior ductility and high strength under different eccentricities. El-Ghazaly et al. (2019) carried out an experimental study on reinforced concrete columns containing ECC and PVA under several types of loading under fire conditions. Their results showed that the ECC and PVA columns showed better stiffness, higher ultimate loads and higher 
ductility than their companions without ECC and PVA. Gernay (2019) developed a finite element model to predict the resistance of reinforced concrete columns under fire exposure. He verified his prediction successfully with a dataset of 74 standard fire resistance tests on columns. He developed also a simple design equation to estimate the burnout resistance from the fire resistance.

\section{Research Significance}

This research covers the gap in the published literature as identified above. Most studies on composites with PVA fibers have been carried out on either small standard laboratory samples, beams or slabs. Limited experimental and theoretical studies were conducted axially loaded high strength columns containing PVA. One study employed the PVA composite as a coating. No tests were conducted on eccentrically loaded columns. In addition, the degradation of columns with PVA fibers due to elevated temperature has not been reported in the literature. The main objective of this research is to study the effect of elevated temperatures on the structural behavior of axially and eccentrically loaded reinforced concrete columns including PVA fibers. The studied variables were different percentages of PVA fibers, different eccentricities of applied loads, and different exposure durations. Comparisons are carried out between specimens having different percentages of PVA fibers and those without fibers to assess the effect of adding PVA fibers on the ultimate load, ultimate deflection, and energy absorption, indicated by the area under the load deflections curves, of eccentrically loaded columns previously exposed to elevated temperatures.

\section{Experimental Programme}

\subsection{Test specimens}

The test specimens consisted of thirty-six reinforced concrete columns with target concrete compressive strength of 30MPa. Cross section of test specimens was constant at $120 \times 120 \mathrm{~mm}$ and two different heights were chosen, $1000 \mathrm{~mm}$ and $1200 \mathrm{~mm}$. The investigated columns parameters included the volumetric ratio of PVA, duration of exposure to elevated temperature and eccentricity of loads. Sixteen columns of height equals $1000 \mathrm{~mm}$ were exposed to concentric axial loads as shown in Figure 1a. Twenty C-shaped specimens of height $1200 \mathrm{~mm}$ were tested under eccentric loads as shown in Figure 1b. All columns have the same vertical and horizontal reinforcement. The specimens were tested with eccentricity ratio of 0.00 (axial), 0.50 and 1.00 . The volumetric ratios of PVA in concrete mixes were nil, $0.75 \%, 1.50 \%$ and $2.25 \%$, respectively. All specimens were exposed to $600^{\circ} \mathrm{C}$ temperatures for $30 \mathrm{~min}$., $60 \mathrm{~min}$. or $120 \mathrm{~min}$. The properties of PVA are reported in Table 1 and the shape of the fibers is shown in Figure 2a and the experimental stress-strain curves for concrete specimens with PVA is given in Figure $2 b$. To avoid local failure, column ends were confined by decreasing arrangement of stirrups from $100 \mathrm{~mm}$ to $40 \mathrm{~mm}$. The height and cross-section of the columns took into account the size capacity of the existing electrical furnace in the laboratory. The concrete cover in all the columns was $15 \mathrm{~mm}$ from the outside of stirrups. The steel used for longitudinal reinforcement consisted of four $12 \mathrm{~mm}$ diameter high grade 40/60 deformed bars. Lateral reinforcement of test columns were fabricated from $8 \mathrm{~mm}$ diameter of mild steel 24/35. Four mixes were designed according to PVA fiber ratio to obtain compressive strength $=30 \mathrm{MPa}$ after 28 days. Mix proportioning of concrete mixes are illustrated in Table 2. Six cubes of dimensions 100 x $100 \times 100 \mathrm{~mm}$, three cylinders of dimensions $100 \times 200 \mathrm{~mm}$ and three cylinders of dimensions $150 \times 300 \mathrm{~mm}$ were cast from each mix and tested to determine properties of hardened concrete, namely compressive, tensile and flexural strength, respectively.

The results recorded in Table 3 showed that adding PVA fibers improved properties of concrete to different degrees. Polyvinyl Alcohol (PVA) fibers effect is much more significant for tensile and flexural strength than that of compressive strength. For example, adding $1.5 \%$ PVA to concrete resulted in compressive strength, tensile strength and flexural strength higher than their companions, without PVA fibers, by $12.7 \%, 112.5 \%$, and 66.4\%, respectively. Kim and Robertson (1997) reported that the compressive strength of PVA modified cement mortar was moderately reduced due to the increase in air void content with the addition of PVA. However, Nuruddin et al. (2015) found that PVA has no effect on the compressive strength of the mixes they tested. In addition, 
Nuruddin et al. (2015), and Holschemacher and Höer (2008) also reported that an increase in volume fraction of PVA fiber increases the splitting tensile strength. Noushini et al. (2013) reported that the modulus of rupture test of control and PVA with $0.25 \%$ and $0.5 \%$ fibre volume fractions versus control exhibited an improvement ranging from $11 \%$ up to $21.5 \%$. It should be noted that Noushini et al. (2013) mixes had a minimum compressive strength of $58 \mathrm{MPa}$, and had a small fiber content. Therefore, the improvement observed in the current investigation, which employed a lower strength concrete and a higher PVA fiber volume, was more than that found in their study. Similar observations were noted by Atahan et al. (2013) who reported that the compressive strength of higher w/c composites benefit more from PVA fiber inclusion compared to lower w/c mixes.

\subsection{Test setup}

The column specimens were tested under framing load with capacity $5000 \mathrm{kN}$ to determine the failure load of columns under a load control scheme with a rate of loading equals $2.0 \mathrm{kN}$ at each increment. A horizontal linear variable differential transformers (LVDT) with stroke was +/- 100 $\mathrm{mm}$ with 0.1 sensitively was placed in the mid-height of column as shown in Figures $3 \mathrm{a}$ and $\mathrm{b}$ to determine the actual lateral deflection which occurs during and after loading. Twenty eight column specimens were exposed to temperature at $600^{\circ} \mathrm{C}$ inside the electrical furnace prior to testing under frame loading in concrete lab as shown in Figure 3a. The electrical furnace consists of eight electrical heaters and its maximum heating temperature is $1200^{\circ} \mathrm{C}$ (see Figures $3 \mathrm{c}$ and d). The behavior of reinforced concrete columns with PVA fibers in terms of ultimate load failure, temperature resistance, stiffness, energy absorption, crack control, and ductility were discussed.

\section{Results and discussion}

All columns were exposed to a constant temperature of $600^{\circ} \mathrm{C}$ first and then tested until failure. The deformation values of the specimens were recorded. The values of ultimate failure load, ultimate deflection, stiffness, energy absorption and ductility for all tested columns were recorded in Table 4. Generally, the inclusion of PVA fibers improves the behavior of reinforced concrete columns in terms of the ultimate load failure, temperature resistance, stiffness, energy absorption, crack control, and ductility.

\subsection{Crack Pattern and Failure Modes}

Generally, it was observed that behavior of columns containing PVA fibers was better than those without fibers. It was observed that micro cracks appeared for PVA columns during loading, and these micro cracks increased with increasing the load until reaching its ultimate failure. Then load started to decrease while concrete has to maintain consistency during failure. The cracking patterns for tested specimens are shown in Figures 4-6. Values of ultimate loads, ultimate deflections, and energy absorption are recorded in Table 4. Columns tested under concentric load without exposure to temperature showed that the first crack appears at load level of nearly $78 \%$ of the column failure load. On the other hand, columns subjected to concentric load and exposed to temperature showed that the first crack started at load level of approximately $50 \%$ of columns' failure load. This is probably due to the reduction in column stiffness because of temperature and hair cracks appearing on surface. Significant concrete spalling occurred in normal reinforced concrete columns, without fibers, while minor signs of spalling were observed in the columns with PVA fibers due to the role of these fibers bridging effect. Polyvinyl Alcohol (PVA) can delay the appearance of cracks and it improves the damage tolerance of the members. As the time of exposure increased, cracks began to appear which further propagated resulting in spalling. The cracks in the columns progressed at the corners of the cross section and led to spalling of chunks of concrete as the columns underwent failure because of the stress concentration near corners. The columns though susceptible to thermal spalling can be safeguarded by using extra PVA fibers. 
For eccentrically loaded specimens, the cracks initially occurred at approximately $15 \%$ to $30 \%$ of the maximum load. With a larger load eccentricity, the applied moment becomes larger and the matrix cracking strength is thus more likely to be reached. The flexural cracks initially appeared on the side far from the loading point and extended towards the opposite side with the increase of applied load. Crack localization occurred beyond the peak load for the columns containing PVA fibers with a load eccentricity of $150 \mathrm{~mm}$, while it was not observed for companion columns with a load eccentricity of $75 \mathrm{~mm}$ during the entire loading process. It was noticed that adding PVA fibers led to reduction of the crack widths, increase of the number of cracks and the shear cracks became less pronounced. In addition, the inclusion of PVA fibers helped to increase the temperature resistance. This was indicated by the reduction of spalling. A tension-softening process occurs in conventional concrete once its tensile strength is obtained followed by a rapid increase in crack width. However for PVA-concrete, following initial cracking, the tensile load continued to increase with strain hardening behavior, accompanied by multiple cracks. Each individual crack tends to open steadily up to a certain crack width and the increasing deformation results in the formation of an additional crack. With the same cracking mechanism, PVA member cracking can reach a saturated state with small crack spacing, until localization of a random single crack occurs. Osman et al. (2019) noted that there is a bridging effect of fiber which inhibit the expansion of cracks during testing and restrain the crack width. Furthermore, it can enhance the lateral restraint performance of concrete when it is damaged.

\subsection{Load-deflection Curves for Studied Columns}

Three groups, according to applied eccentricity, were tested to study the effect of amount of PVA fibers on the behavior of eccentrically and concentrically loaded columns at room temperature and elevated temperature. The specimens were provided with $0.00,0.75,1.50$ or $2.25 \%$ volumetric ratio of the PVA fibers as indicated in Table 4. The load displacement curves of different studied specimens are shown in Figures 7-9 and the values of ultimate load, ultimate deflection, and energy absorption were recorded in Table 4. The figures show, generally, that the provision of the PVA enhance the ultimate capacity of the columns. In addition, the ultimate capacity of column specimens decreased with increasing the duration time of temperature exposure. It was observed also that no signs of spalling appeared on columns containing PVA fibers. This may be attributed to the fiber bridging effect, or in other words, when concrete exposed to high temperature, the PVA fibers melts creating paths to escape water vapor, which was captured in pore structure of concrete, in order to give concrete room to breathe, to prevent explosions and, in turn, to increase its resistance (Osman et al., 2019). Cao et al. (2019) also observed no spalling in samples with PVA exposed to elevated temperature.

\subsubsection{Concentric columns (axially loaded)}

Figure 7 shows the load deflection relations for specimens including different PVA ratios and subjected to different overheating time durations at zero eccentricity. It can be seen from Figure $7 \mathrm{a}$ and Table 4 that the ultimate capacities for concentric column specimens C14, C18, C21, which contain PVA percentages of $0.75,1.5,2.25$, and tested at room temperature, were higher than that of $\mathrm{C} 1$, with no PVA, by $4 \%, 12 \%$ and $8 \%$, respectively. This shows that the maximum enhancement in the axial capacity for specimens was at $1.5 \%$ fiber content and that was for Specimen C18. It can be argued that increasing the PVA percentage higher than $1.5 \%$ did not lead to further improvement in column's capacity. Figure 7b shows the load deflection relationship for specimens, C4, C13, C19, and C22 containing different percentages of PVA, that were exposed to overheating for $30 \mathrm{~min}$, during concentric loading. The maximum enhancement for the ultimate capacity was for Specimen $\mathrm{C} 19$ and it was higher than that of Specimen C4 by 15\%. Figure 7c shows the load deflection relationships for specimens exposed to temperature duration of $60 \mathrm{~min}, \mathrm{C} 7, \mathrm{C} 15, \mathrm{C} 20$ and $\mathrm{C} 23$ and having different PVA ratios. It can be seen from Figure $7 \mathrm{c}$ and Table 4 that the ultimate capacity of specimens C15, C20, and C23 were higher than that of Specimen C7, with no PVA fibers, by 5\%, $24 \%$, and $20 \%$, respectively. Figure $7 \mathrm{~d}$ shows the load deflection relationships for specimens, C10, 
$\mathrm{C} 16, \mathrm{C} 17$, and $\mathrm{C} 24$, exposed to overheating duration of $120 \mathrm{~min}$. It can be seen from the figure that Specimen C17, with $1.5 \%$ PVA, had the maximum enhancement of the ultimate capacity which was $20 \%$ higher than that of Specimen C10, which had no fibers.

It can be seen from Figure 7 and Table 4 that the ultimate capacity of the columns rapidly decreased with increasing the duration of temperature exposure to different degrees depending on the percentage inclusion of PVA fibers. For example, the ultimate loads of specimens without fiber, C4, $\mathrm{C} 7$, and $\mathrm{C} 10$, and subjected to 30,60 , and $120 \mathrm{~min}$. temperature exposure, were lower than that of $\mathrm{C} 1$, tested in room temperature, by $20.3 \%, 36.7 \%$, and $61 \%$, respectively. For specimens containing $0.75 \%$ PVA, the ultimate loads of Specimens C13, C15, and C16, and subjected to 30, 60, and 120 min. temperature exposure, were lower than that of Specimen C14, tested at room temperature by $21.1 \%, 36.3 \%$, and $61 \%$, respectively. For specimens containing 1.5\% PVA, the ultimate loads of Specimens C19, C20 and C17, and subjected to 30, 60, and $120 \mathrm{~min}$. temperature exposure, were lower than that of $\mathrm{C} 18$, tested at room temperature by $18 \%, 30 \%$, and $58 \%$, respectively. Finally, for specimens containing 2.25\% PVA, the ultimate load of specimens C22, C23 and C24, and subjected to 30,60 , and $120 \mathrm{~min}$. temperature exposure, were lower than that of $\mathrm{C} 21$, tested at room temperature by $19.5 \%, 30 \%$, and $60 \%$, respectively. Cao et al. (2019) reported that PVA fibers will melt under elevated temperatures, and holes will be formed in the concrete, which can effectively release the concrete vapor pressure and suppress the incidence of concrete spalling or crumbling.

\subsubsection{Eccentric columns (Eccentricity ratio, $\mathrm{e} / \mathrm{t}=\mathbf{0 . 5 0}$ )}

Figure 8 shows the load-deflection relationships for column specimens tested at eccentricity ratio, e/t, of 0.50 , with and without fibers in room temperature or in different durations of temperature exposure. It is worth defining the eccentricity, e, as the distance from point of application of load to the neutral axis, $t$, as the column depth, and the eccentricity ratio, e/t, as the distance between the location of applied load and axis of column to total depth of the column. Figure 8a shows that the ultimate capacity of Specimen C25, including 0.75\% PVA, was approximately 1.10 times that of Specimen C2 which had no fiber addition. Figure $8 \mathrm{~b}$ shows the load deflection relationships for specimens subjected to temperature exposure duration, $30 \mathrm{~min}$., C5, C27, C33 and C35. It can be seen from the figure that the ultimate loads of specimens $\mathrm{C} 27, \mathrm{C} 33, \mathrm{C} 35$, which include $0.75 \%$, $1.5 \%$, and $2.25 \%$ PVA fibers, were higher than that of $\mathrm{C} 5$, which had no fibers, by $11 \%, 26 \%$ and $33 \%$, respectively. Figure 8c shows that the ultimate load of Specimen C29, including 0.75\% PVA, exposed to temperature for one hour, was higher than that of $\mathrm{C} 8$, with no fibers, by $21 \%$. Figure $8 \mathrm{~d}$ shows that the ultimate load of specimen C31, including 0.75 PVA, and exposed to temperature for two hours was higher than its companion, C11, without fibers, by $23 \%$. Figure 8 shows also that the ultimate load of specimens $\mathrm{C} 5, \mathrm{C} 8$, and $\mathrm{C} 11$, which had no PVA fibers and exposed to temperature for 30, 60, 120 min., was lower than that of their companion $\mathrm{C} 2$, tested at room temperature, by $17.6 \%, 41 \%$, and $61 \%$, respectively. For specimens with PVA fiber content of $0.75 \%$, and subjected to 30,60 , and $120 \mathrm{~min}$. temperature exposure, the ultimate loads of specimens C27, C29 and C31 were lower than that of Specimen C25, tested in room temperature, by $16.5 \%, 34.8 \%$, and $56 \%$, respectively.

\subsubsection{Eccentric columns ( $($ Eccentricity ratio, $e / t=1.0)$}

The load deflection relationships for specimens tested at eccentricity ratio, e/t, of 1.0, with and without fibers are shown in Figure 9. The values of ultimate loads, ultimate deflection, and energy absorption were recorded in Table 4. Figure 9a shows that the ultimate load of Specimen C26, with $0.75 \%$ PVA, was approximately 1.13 times that of Specimen C3, with no fibers, at room temperature. Figure $9 \mathrm{~b}$ shows load deflection relationships for specimens C6, with no fibers and C28, including $0.75 \%$ PVA after $30 \mathrm{~min}$. exposure to temperature. It can be seen from the figure that ultimate load of Specimen C28 was higher than that of C6 by $10 \%$. After exposure to temperature for one hour, Figure 9c shows the load deflection relations for specimens C9, C30, C34, and C36 which include no fibers, $0.75 \%$ PVA, $1.50 \%$ PVA, and $2.25 \%$ PVA, respectively. It can be seen from the figure that the ultimate loads for $\mathrm{C} 30, \mathrm{C} 34$, and, $\mathrm{C} 36$ were higher than that of $\mathrm{C} 9$ by 
9.50\%, 25.40\%, and 34.90\%, respectively. Figure 9d shows the load deflection relationships for specimens $\mathrm{C} 12$, with no PVA fibers, and C32, including $0.75 \%$ PVA after temperature exposure for two hours. It can be seen from the figure that the ultimate load of C32 was higher than that of C12 by $12.50 \%$. Figure 9 shows also that Specimens without PVA fibers, C6, C9, C12 and tested after temperature exposure for 30, 60, $120 \mathrm{~min}$, had ultimate loads lower than their companion, C3, tested at room temperature, by $18 \%, 37 \%$, and $60 \%$, respectively. It can be seen from the figure also that Specimens C28, C30, C32, included 0.75\% PVA, and tested after exposure to overheating for 30, 60, 120 min., had ultimate loads lower than their companion, C26, tested in room temperature, by $20.3 \%, 38.9 \%$, and $60.1 \%$, respectively.

\subsection{Energy Absorption}

Energy absorption is defined as the area under load deflection curve; i.e. it is a function of ultimate load and ultimate deflection. Therefore it can be a good indication of the effect of PVA fibers and an index of the ductility of studied specimens. The values of energy absorption of different studied specimens were recorded in Table 4. It was noticed from Table 4 that, generally, the energy absorption increases by increasing PVA fiber content to different degrees, depending on duration of exposure to temperature. It can be seen from Table 4 and Figure 7 that, for tested concentric columns, the energy absorption of Specimen C18 is higher than that of Specimen C1 by $107 \%$ after testing in room temperature. Testing after $30 \mathrm{~min}$. duration of temperature exposure led to an energy absorption of $\mathrm{C} 19$ higher than that of $\mathrm{C} 4$ by $96 \%$. Increasing duration time of temperature to one hour resulted in an energy absorption of $\mathrm{C} 20$ higher than that of $\mathrm{C} 7$ by $90.8 \%$. The energy absorption of Specimen C17, tested after two hours exposed to temperature, was higher than that of $\mathrm{C} 10$ by $56.50 \%$. For columns tested at e/t $=0.50$, Figure 8 and Table 4 show that the maximum increase in the energy absorption was for C35, containing $2.25 \%$ PVA, and it was higher than that of $\mathrm{C} 5$ by $109 \%$. Further increase to eccentricity ratio, e/t=1, Figure 9 and Table 4 show that the energy absorption of C36, containing $2.25 \%$ PVA, was higher than that of C9, with no fibers, by $84.1 \%$. For specimens exposed to different durations of temperature exposure and axially loaded, the highest energy absorption was for $1.5 \%$ inclusion of PVA fibers as shown in Figure 10 and indicated in Table 4.

It can be seen from the above discussion that increasing the fiber content led to improving the behavior of tested columns after overheating exposure. It can be seen from Figures 7-9 a noticeable drop in the overall stiffness of columns subjected to temperature. It is obvious that the reduction of stiffness and elastic modulus of concrete increased with increasing the duration of temperature exposure. Other researchers recommended the inclusion of polyethylene fiber and/or PVA in concrete. For example, Gholampour et al. (2019) and Xaio et al. (2018) recommended using polyethylene fiber in columns especially for buildings in seismic regions and they demonstrated that adding these fibers can significantly increase the energy absorption of reinforced concrete structure. Atahan et al. (2013) tested the Charpy impact resistance of composites with 0.5 and $2.0 \%$ PVA fibers by volume having w/c of 0.25 or 0.35 . They concluded that depending on the matrix strength properties, the specific fracture energy can be improved by 20 and 45 times with $2 \%$ volume fraction ratio PVA fibers. At temperatures below $400^{\circ} \mathrm{C}$, which are above the melting point of the PVA fibers, Li et al. (2016) reported that nearly $40 \%$ of flexural stress and stiffness were lost. However, with higher temperature exposure not only the fiber bridging action is seriously destroyed, but also the hydration products decompose. After exposure to $800^{\circ} \mathrm{C}$, residual flexural stress and stiffness were only approximately 30 and $16 \%$ of their original values, respectively. It should be noted that their mixes were ultra-high toughness cementitious composites (UHTCC), containing PVA and steel fibers in addition to Nano $\mathrm{SiO} 2$.

\section{Conclusions}

This investigation studied the effect of temperature exposure on the behavior of reinforced concrete columns containing PVA fibers under centric and eccentric loadings. Based on the experimental 
results presented in this paper, the main conclusions can be drawn as the follows:

1. Generally, the reinforced concrete columns containing PVA fibers had ultimate loads higher than those of normal reinforced concrete columns without fibers. Increasing the fiber content led to improving the behavior of tested columns after overheating exposure.

2. It was noticed that adding PVA fibers led to reduction of the crack widths, increase of the number of cracks and the shear cracks became less pronounced. The inclusion of PVA fibers helped to increase the temperature resistance and this was indicated by the reduction of spalling.

3. For axially loaded columns, adding $1.50 \%$ PVA was enough to obtain the highest values of ultimate load, ultimate deflection, energy absorption, and, in turn, ductility. For eccentric columns, increasing the percentage of PVA from $1.5 \%$ to $2.25 \%$ resulted in increasing the values of ultimate load, ultimate deflection, and energy absorption.

4. It was found that the ultimate load of the columns exposed to temperature rapidly decreased with increasing the duration of temperature to different degrees depending on the percentage inclusion of PVA fibers and load eccentricity. Ultimate loads for columns under load eccentricity ratio of 1.0 and including $0.75 \%$ PVA only were reduced by $16 \%, 33 \%$, and $52 \%$ for temperature duration of $30 \mathrm{~min}$., $60 \mathrm{~min}$., and $120 \mathrm{~min}$. compared to companion tested in room temperature.

5. It was found that ductility and energy absorption for columns including 1.5\% PVA were higher than their companions without fibers after temperature exposure. It was observed that the energy absorption of eccentric columns exposed to temperature for up to two hours was still higher than that of their companions without fibers by $40 \%$ for eccentricity ratio of 1.0 .

\section{References}

Al-Gemeel, A. N., and Zhuge, Y., 2018, "Experimental investigation of textile reinforced engineered cementitious composite (ECC) for square concrete column confinement", Construction and Building Materials, Vol. 174, pp. 594-602. https://doi.org/10.1016/j.conbuildmat.2018.04.161

Atahan, H. N., Pekmezci B. Y., and Tuncel, E. Y., (2013). Behavior of PVA Fiber-Reinforced Cementitious Composites under Static and Impact Flexural Effects. Journal of Materials in Civil Engineering, 25(10), pp. 1438-1445. DOI: 10.1061/(ASCE)MT.1943-5533.0000691

Cai, J., Pan, J., and Li, X., 2018 (a), "Behavior of ECC-encased CFST columns under axial compression”, Engineering $\quad$ Structures, Vol. $171, \quad$ pp. 1-9. https://doi.org/10.1016/j.engstruct.2018.05.090

Cai, J., Pan, J., and Lu, C., 2018 (b), "Mechanical behavior of ECC-encased CFST columns subjected to eccentric loading", Engineering Structures, Vol. 162, pp. 22-28. https://doi.org/10.1016/j.engstruct.2018.02.029

Cao, R., Yang, H., Lu, G., (2019) "Effects of High Temperature on the Burst Process of Carbon Fiber/PVA Fiber High-Strength Concretes”, Materials, 12, 973, doi:10.3390/ma12060973

El-Ghazaly, H., A., Abd El-Azim, A., Said, M., Ali, 2019, "Behavior of Reinforced Concrete Columns with (PVA) Under Fire", Al Azhar University Civil Engineering Research Magazine (CERM) Vol. 441, No. 3, pp. 54-64.

Feng, J.; Sun, W.; Zhai, H.; Wang, L.; Dong, H.; Wu, Q., (2018). Experimental Study on Hybrid Effect Evaluation of Fiber Reinforced Concrete Subjected to Drop Weight Impacts. Materials, 11, 2563, doi:10.3390/ma11122563.

Gernay, T., 2019, "Fire resistance and burnout resistance of reinforced concrete columns", Fire Safety Journal, Vol. 104, pp. 67-78. https://doi.org/10.1016/j.firesaf.2019.01.007

Gholampour A., Hassanli R., Mills J. E., Vincent T., and Kunieda M., (2019) "Experimental investigation of the performance of concrete columns strengthened with fiber reinforced concrete 
jacket" Construction and Building Materials, Vol. 194, pp. 51-61.

Hamoush, S., Abu-Lebdeh, T. and Cummins, T. (2010). Deflection behavior of concrete beams reinforced with PVA micro-fibers, Construction and Building Materials, 24, pp. 2285-2293. doi:10.1016/j.conbuildmat.2010.04.027

Holschemacher, K., and Höer, S. (2008). "Influence of PVA fibers on load carrying capacity of concrete with coarse aggregates." 7th Int. Rilem Symp. on Fibre Reinforced Concrete: Design and Applications, BEFIB, 219-229.

Horikoshi, T., Ogawa, A., Saito, T., and Hoshiro, H., (2006). Properties of Polyvinyl alcohol fiber as reinforcing materials for cementitious composites, in Proc., Int'1 RILEM Workshop on High Performance Fiber Reinforced Cementitious Composites in Structural Application, RILEM Publications SARL, pp. 145-153.

Jang, J.G., Kim, H.K., Kim , T.S., Min, B.J., and Lee, H.K. (2014). Improved flexural fatigue resistance of PVA fiber-reinforced concrete subjected to freezing and thawing cycles, Construction and Building Materials, 59, pp 129-135, http://dx.doi.org/10.1016/j.conbuildmat.2014.02.040

Kim, J.H. and Robertson, R.E. (1997) Prevention of air void formation in polymer-modified cement mortar by pre-wetting, Cement and Concrete Research, 27 (2), pp. 171-176, http://dx.doi.org/10.1016/S0008-8846(97)00001-X.

Kim, J.H. and Robertson, R.E. (1997) Prevention of air void formation in polymer-modified cement mortar by pre-wetting, Cement and Concrete Research, 27 (2), pp. 171-176, http://dx.doi.org/10.1016/S0008-8846(97)00001-X.

Kou, S.C. and Poon, C.S. (2010), Properties of concrete prepared with PVA-impregnated recycled concrete aggregates, Cement and Concrete Composites, 32 (8), pp. 649-654, http://dx.doi.org/10.1016/j.cemconcomp.2010.05.003.

Li Q., Gao, X., Xu, S., Peng, Y., Fu, Y. (2016) Microstructure and mechanical properties of hightoughness fiber-reinforced cementitious composites after exposure to elevated temperatures. Journal of Materials in Civil Engineering, 28(11): 04016132, https://doi.org/10.1061/ (ASCE)MT.19435533.0001647

Magalha es M.S., Toledo Filho R.D., Fairbairn E.M.R. (2013). Durability under thermal loads of polyvinyl alcohol fibers. Mate'ria (Rio J.) 18(4), pp.1587-1595.

Meng D., Huang T., Zhang X., Y., and Lee C., K., (2017) "Mechanical behaviour of a polyvinyl alcohol fibre reinforced engineered cementitious composite (PVA-ECC) using local ingredients" Construction and Building Material, Vol. 141. pp. 259-270.

Nehdi, L. I, Ali, M. A. E. M. (2019), Experimental and Numerical Study of Engineered Cementitious Composite with Strain Recovery under Impact Loading. Applied Science, 9, 994; doi:10.3390/app9050994

Noushini, A., Samali, B. and Vessalas, K., (2013). Effect of PVA fiber on dynamic and material properties of fiber reinforced concrete. Construction and Building Materials, vol. 49, p. 374-383, 2013. doi:10.1016/j.conbuildmat.2013.08.035

Noushini, A., Vessalas, K., and Samali, B., 2014, "Static mechanical properties of polyvinyl alcohol fibre reinforced concrete (PVA-FRC)”, Vol. 66, No. 9, pp. 465-483.

Noushini, A., Samali, B., \& Vessalas, K. (2015). Ductility and Damping Characteristics of PVAFRC Beam Elements. Advances in Structural Engineering, 18 (11), pp. 1763-1787.

Nozawa, T., Choi, J-H., Hattori, M., Otsuka, H., (2017). Cyclic loading test for columns made with ultra-strength fiber-reinforced concrete and trace analyses using finite element analyses. Structural Concrete. 18, pp. 433-443. https://doi.org/10.1002/suco.201600053

Nuruddin M.F., Ullah Khan S., Shafiq N., Ayub T. (2015). Strength prediction models for PVA fiber-reinforced high-strength concrete. Journal of Materials in Civil Engineering, 27(12). DOI: 10.1061/(ASCE)MT.1943-5533.0001279 
Osman, B. H., Sun, X., Tian, Z., Lu, H.and Jiang, G. (2019). "Dynamic compressive and tensile characteristics of a new type of ultra-high-molecular weight polyethylene (UHMWPE) and polyvinyl alcohol (PVA) fibers reinforced concrete," Shock and Vibration, vol. 2019, Article ID 6382934, 19 pages,

Özbay, E., Türker, H. T., Balçıkanlı, M. and Lachemi, M., (2015). Effect of Fiber Types and Elevated Temperatures on the Bond Characteristic of Fiber Reinforced Concretes, International Journal of Civil and Environmental Engineering Vol: 9, No: 5, pp. 549-553.

Pan, J.L.,Gu, J., Chen, J.H., (2015) "Theoretical modeling of steel reinforced ECC column under eccentric compressive loading", SCIENCE CHINA, Technological Sciences, 58 (5), pp 889-898, doi: 10.1007/s11431-015-5798-Z

Pourfalah, S., (2018). Behaviour of engineered cementitious composites and hybrid engineered cementitious composites at high temperatures. Construction and Building Materials, 158, pp. 921937. https://doi.org/10.1016/j.conbuildmat.2017.10.077

Şahmaran M.,Özbay, E., Yücel,H.E., Lachemi, M., and Li, V. C., (2011) "Effect of fly ash and PVA fiber on microstructural damage and residual properties of engineered cementitious composites exposed to high temperatures" J. of Material in Civil Engineering, Vol. 23, Issue 12, pp. 1735-1745.

Xiao J., Xie Q., Xie W L., (2018) "Study on high-performance concrete at high temperatures in China (2004-2016) - An updated overview” Fire Safety Journal, Vol. 95, pp. 11-24.

Said, S. H., Abdul Razak, H. and Othman, I. (2015). Flexural behavior of engineered cementitious composite (ECC) slabs with polyvinyl alcohol fibers. Construction and Building Materials, 75, pp. 176-188. https://doi.org/10.1016/j.conbuildmat.2014.10.036

Thong, C. C., Teo, D. C. L., and Ng, C. K. (2016). "Application of polyvinyl alcohol (PVA) in cement-based composite materials: A review of its engineering properties and microstructure behavior." Construction and Building Materials, 107, pp. 172-180, http://dx.doi.org/10.1016/j.conbuildmat.2015.12.188

Wang, S. and Li, V.C., (2006). Polyvinyl Alcohol Fiber Reinforced Engineered Cementitious Composites: Material Design and Performances, in Proc., Int'1 RILEM Workshop HPFRCC in Structural Applications, Eds. Fischer, G., and V.C. Li, published by RILEM SARL, pp. 65-73.

Xu, Z., Wang, T. and Wang, W. (2018). Effect of PVA fiber content on creep property of fiber reinforced high-strength concrete columns. AIP Conference Proceedings 1955, 020026 (2018); https://doi.org/10.1063/1.5033598

Yeganeh, A. E., Hossain, K. M. P. and Anwar, M. S., (2016). Structural behavior of reinforced concrete high performance concrete columns subjected to monotonic axial loading, STR-920-1, Resilient Infrastructure, London, June 2016. https://pdfs.semanticscholar.org/d21f/73ac405a964195fe88280fc4c5ee11f1a65b.pdf

Zhang, X. and Deng, Z. (2018) Experimental study and theoretical analysis on axial compressive behavior of concrete columns reinforced with GFRP bars and PVA fibers, Construction and Building Materials, 172, pp. 519-532, https://doi.org/10.1016/ j.conbuildmat.2018.03.237. 


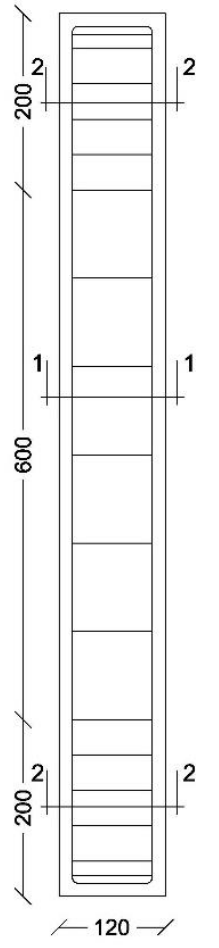

a)
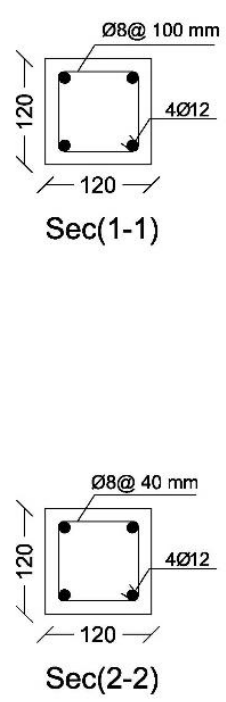

Figure 1 Concrete dimensions and reinforcement details of specimens.

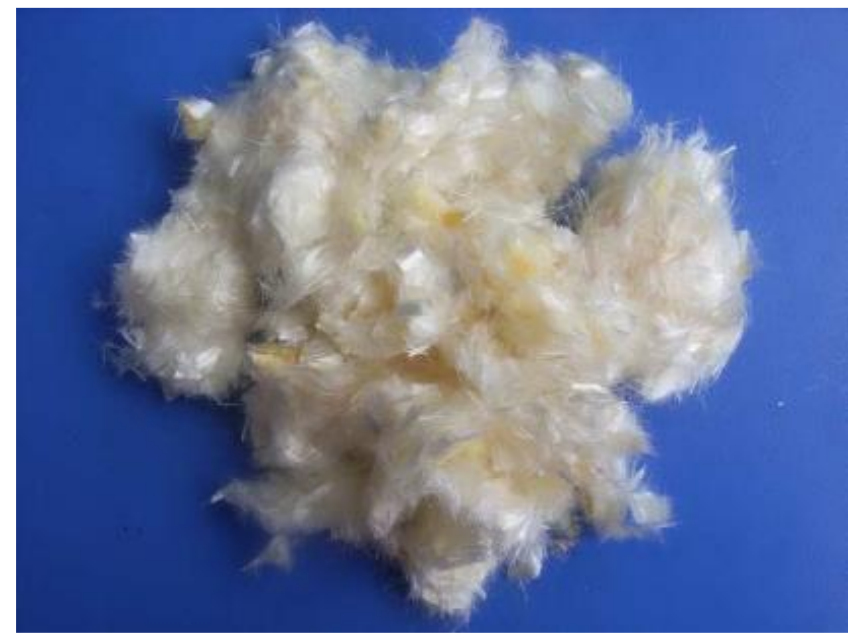

a) Shape of polyvinyl alcohol fibers (PVA)

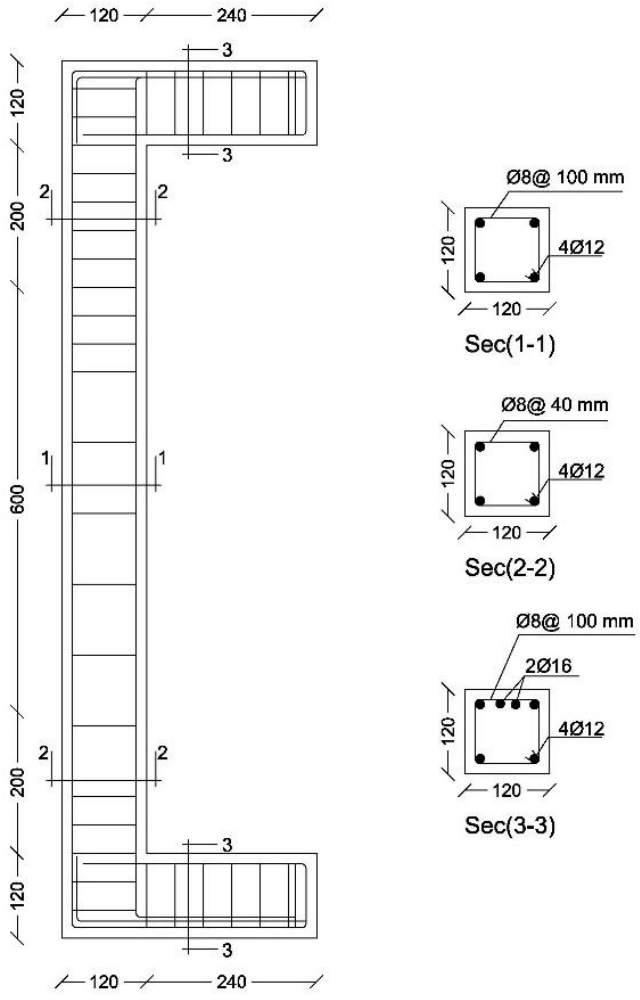

b)

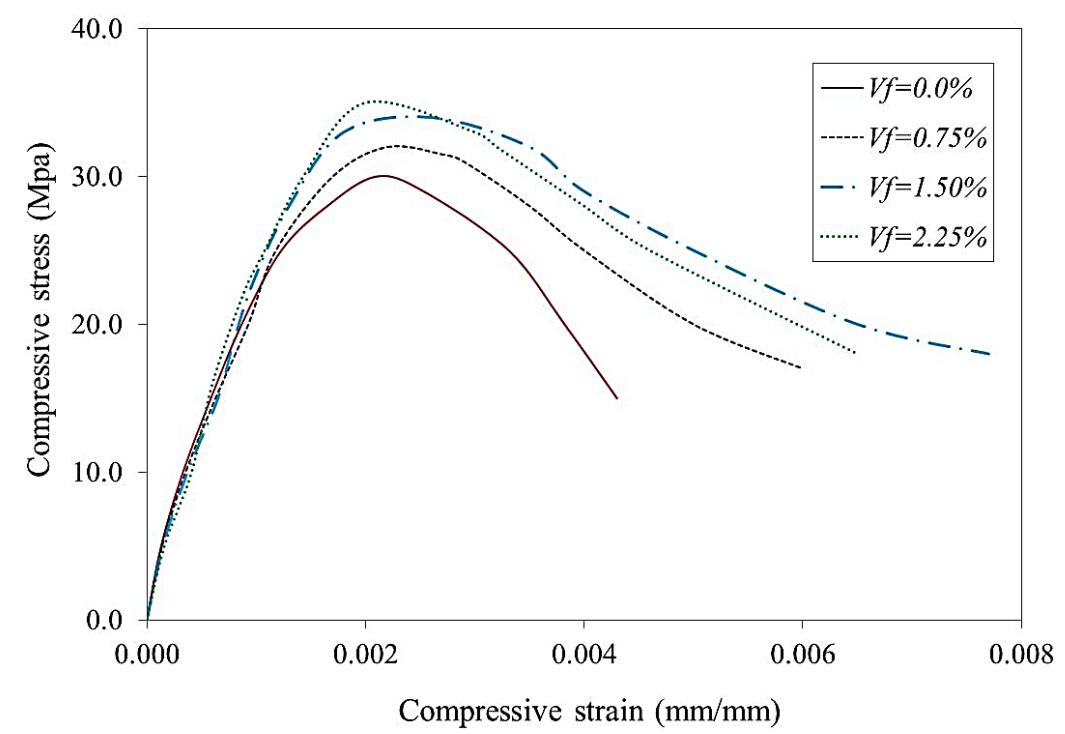

b) Stress strain curves for typical specimens

Figure 2 PVA shape and stress strain curves for concrete containing PVA 


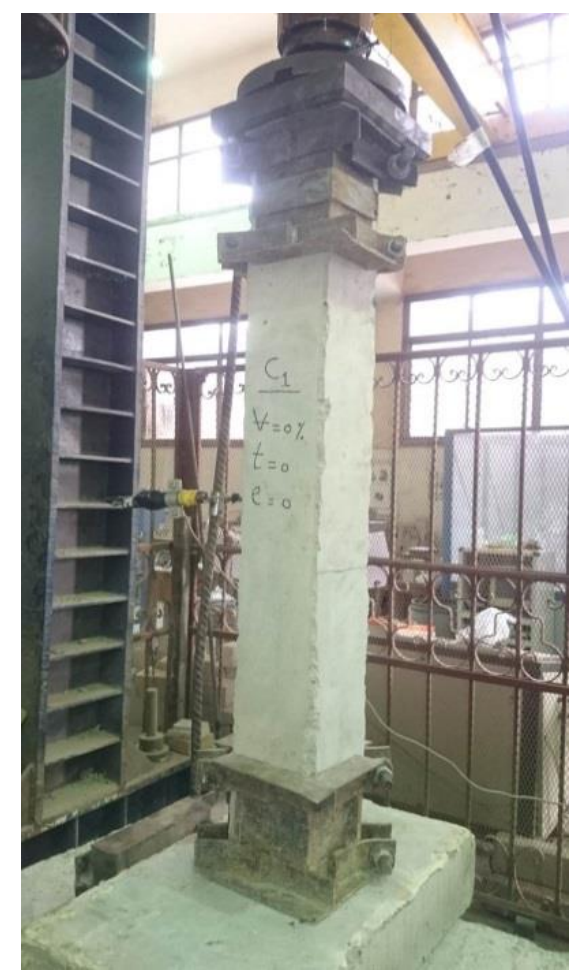

a) Concentric column

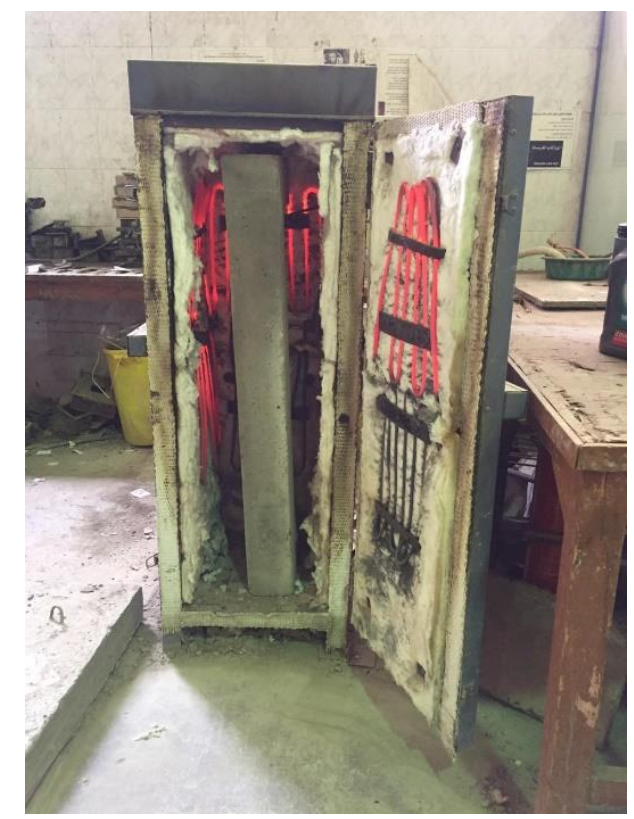

c) Specimen in the furnace

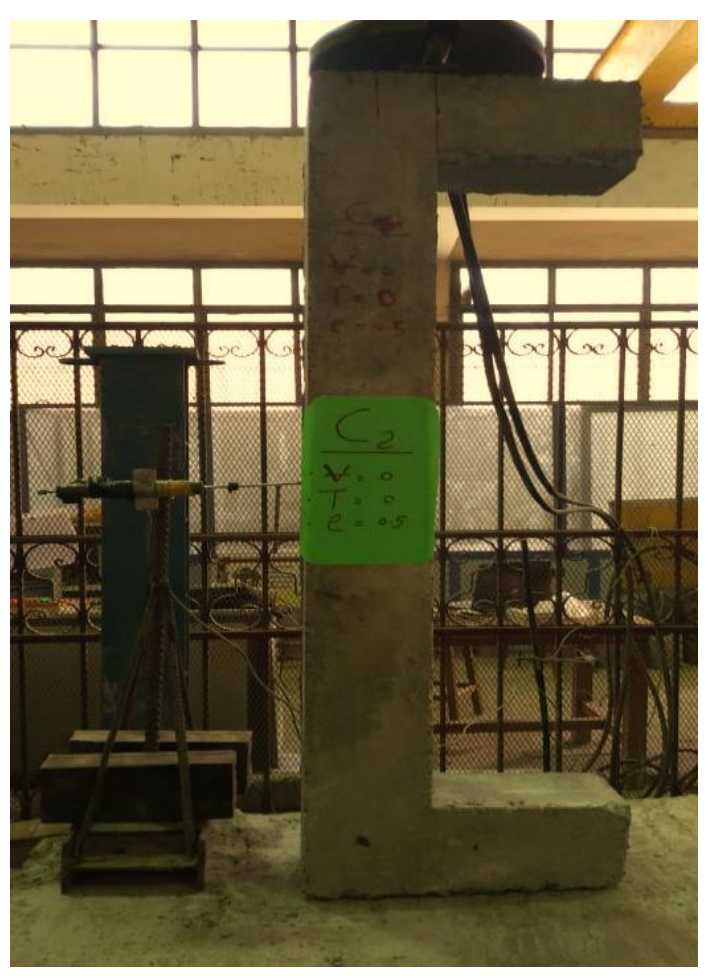

b) Eccentric column

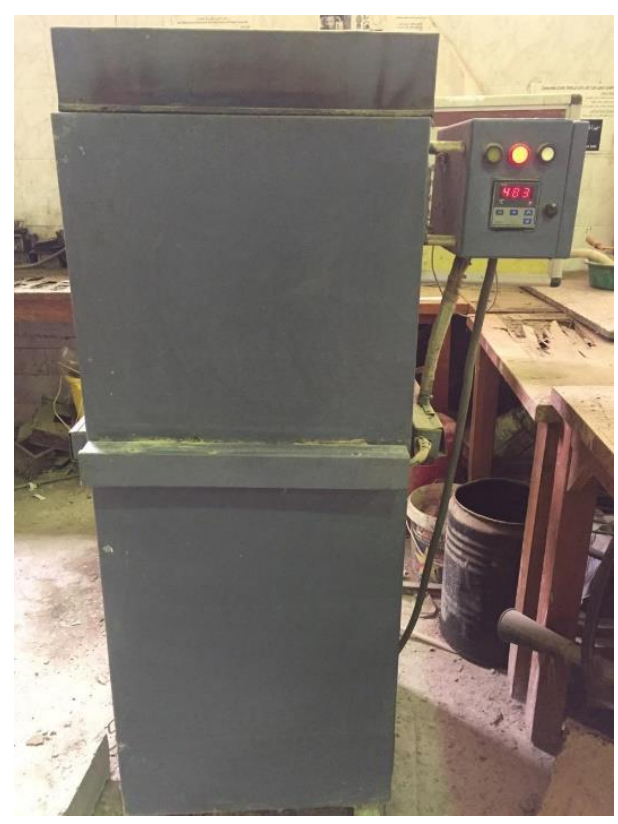

d) During overheating in the furnace

Figure 3 Test setup and exposing specimens to overheating. 


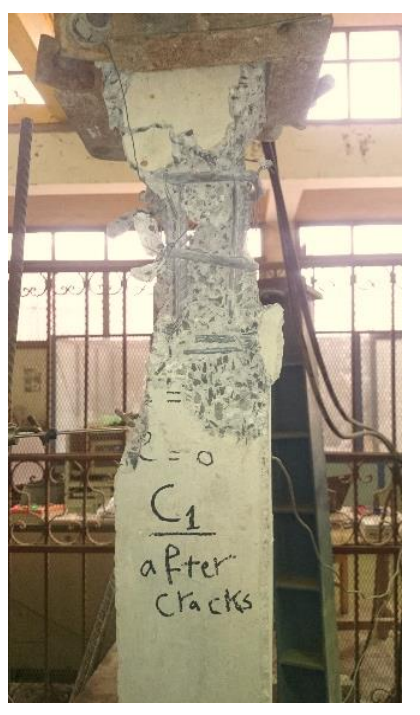

a) Specimen $\mathrm{C} 1$

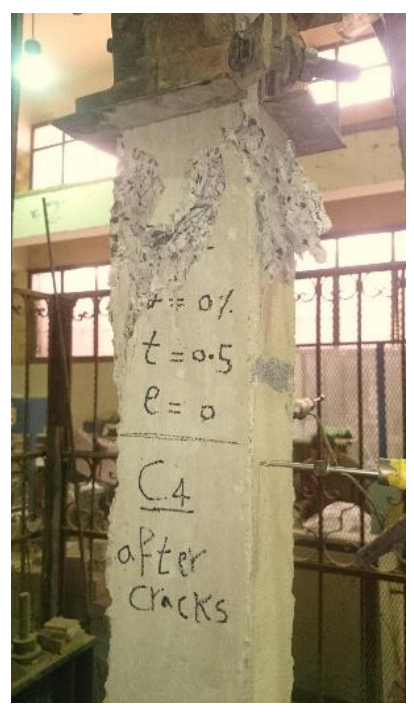

b) Specimen C4

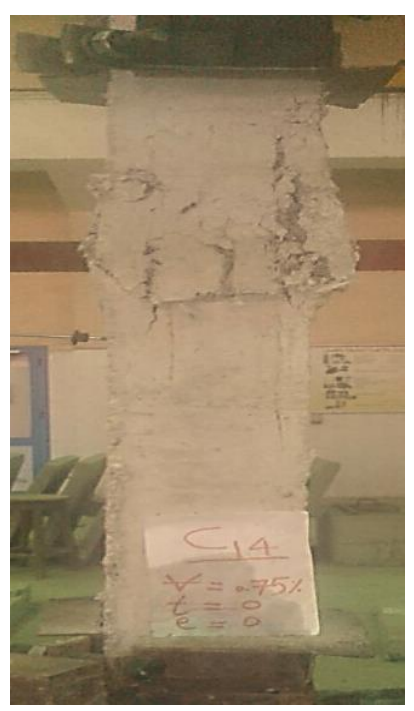

c) Specimen C14

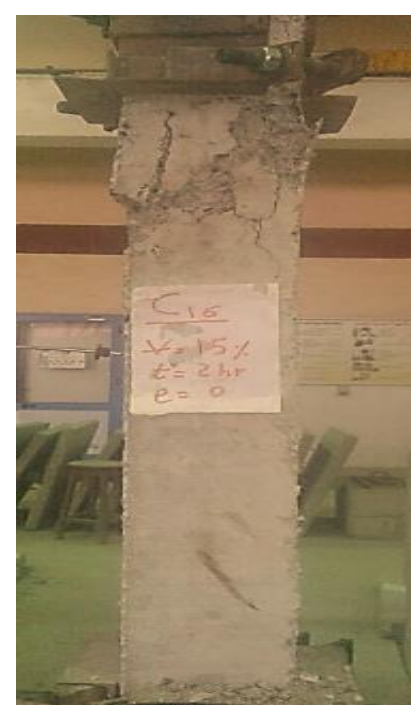

d) Specimen C16

Figure 4 Crack pattern and failure of columns tested under concentric loads. 


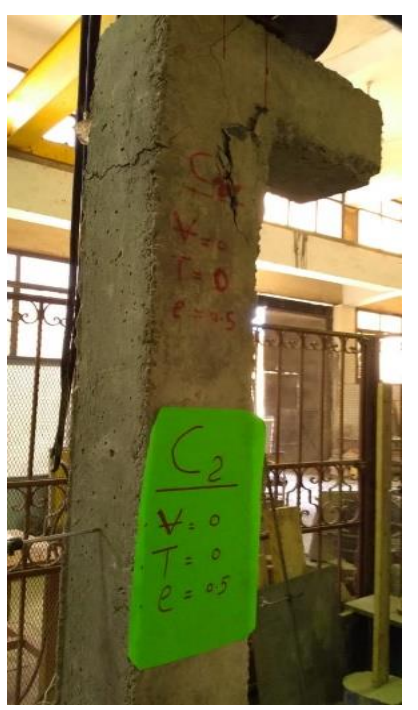

a) Specimen C2

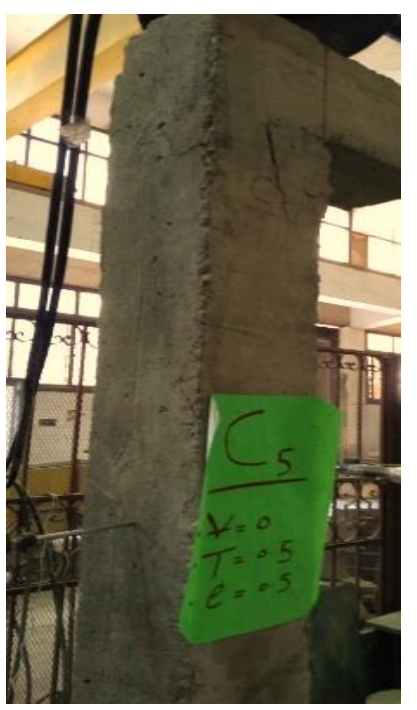

b) Specimen C5

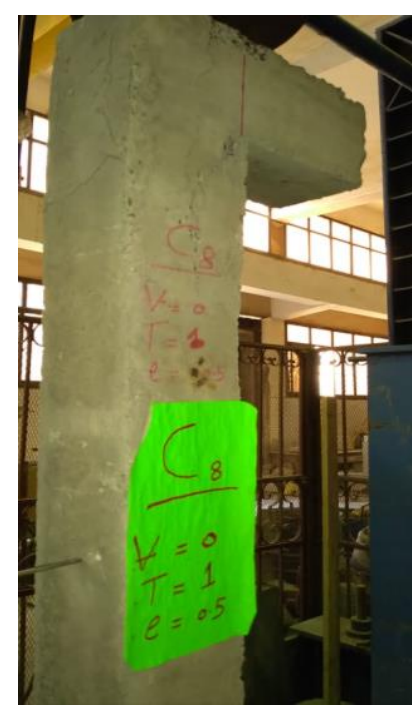

c) Specimen $\mathrm{C} 8$

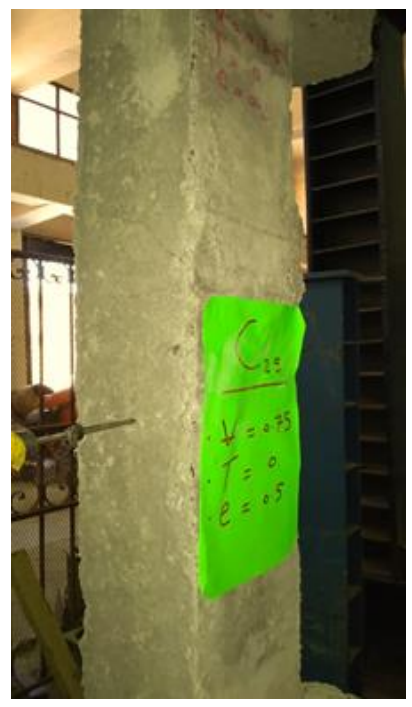

d) Specimen C25

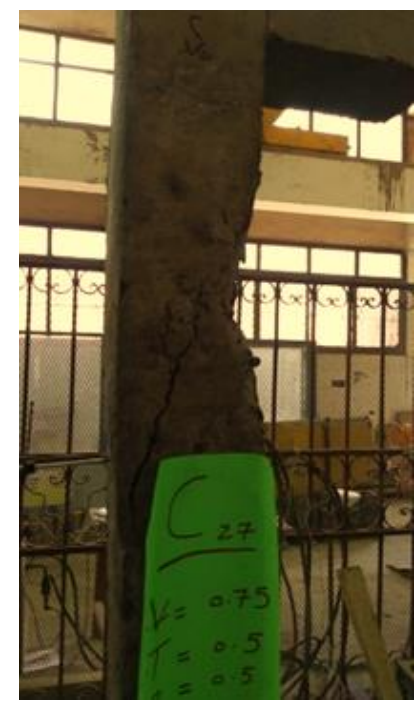

e) Specimen C27

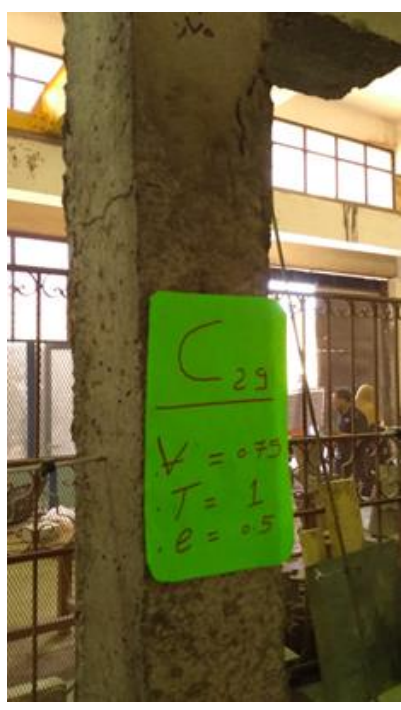

f) Specimen C29

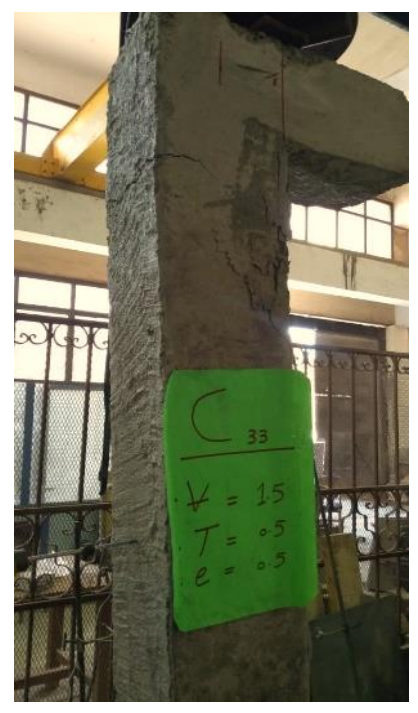

g) Specimen C33

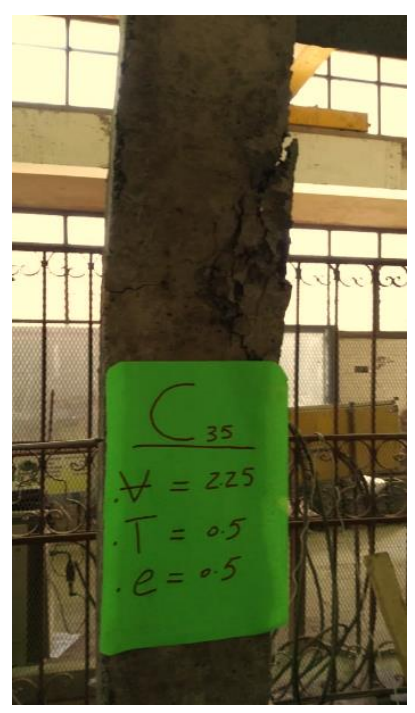

h) Specimen C35

Figure 5 Crack pattern and failure of columns tested under eccentric loads, eccentricity ratio, $\mathrm{e} / \mathrm{t}=0.50$. 


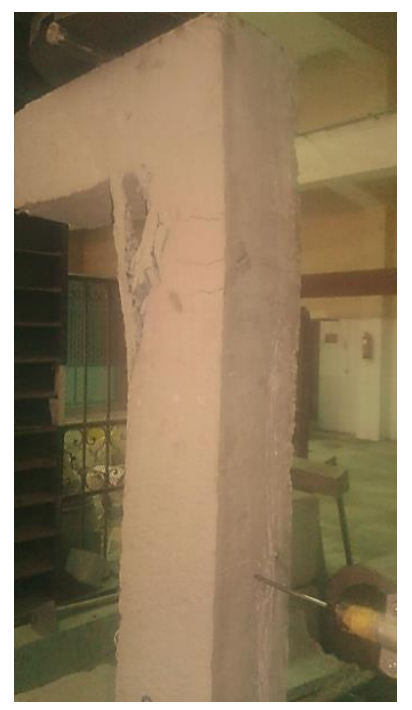

a) Specimen C3

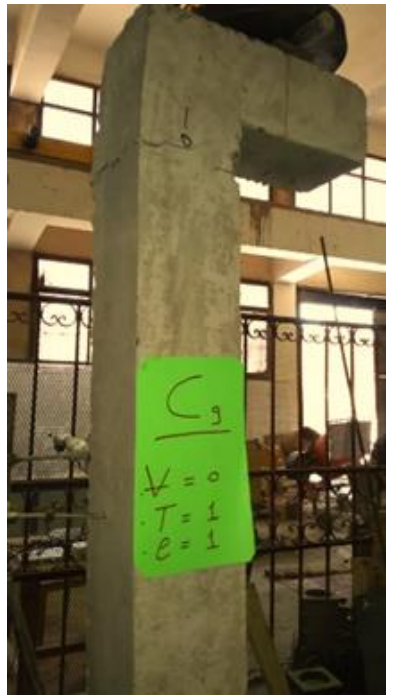

b) Specimen C9

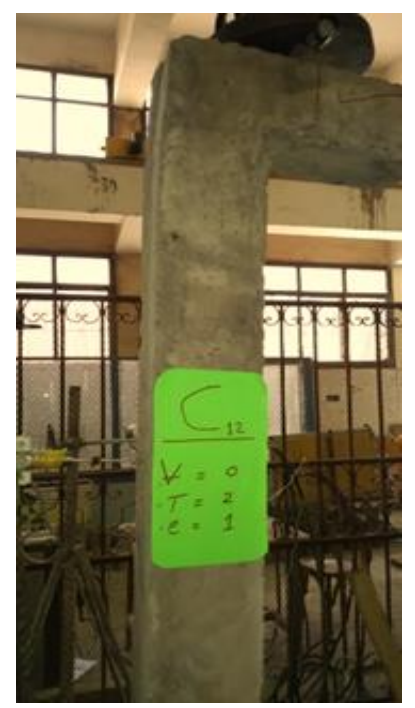

c) Specimen C12

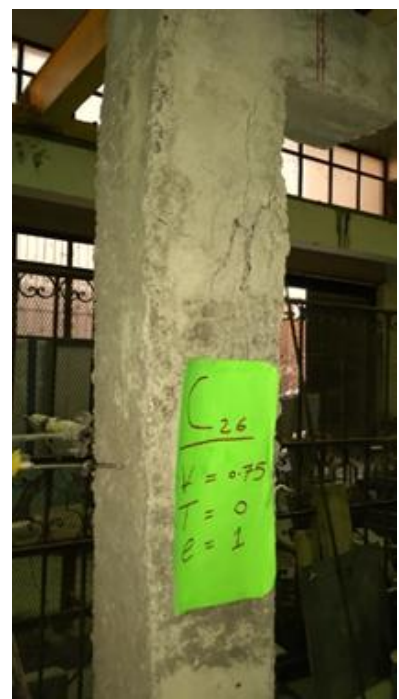

d) Specimen C26

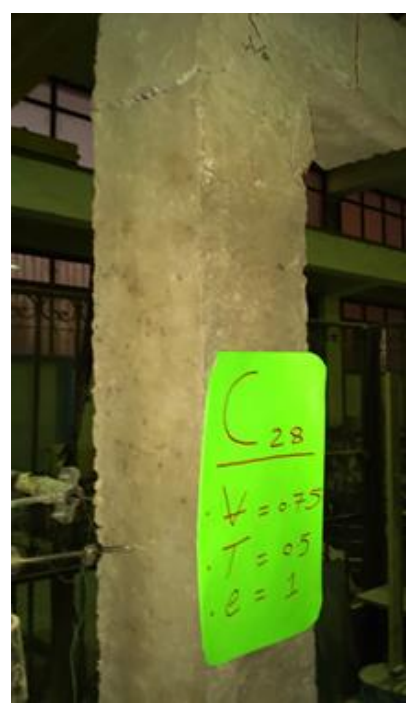

e) Specimen C28

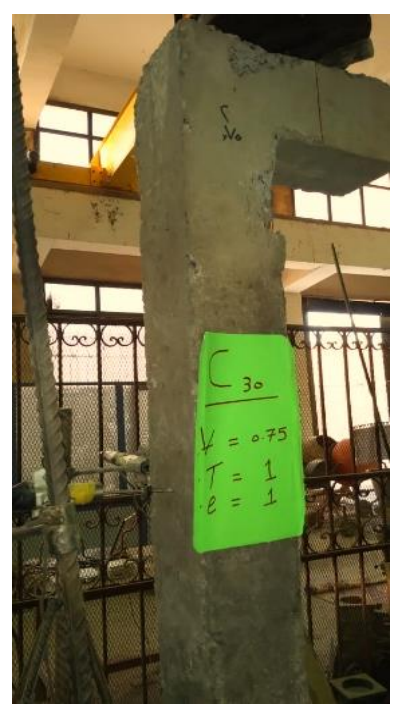

f) Specimen C30

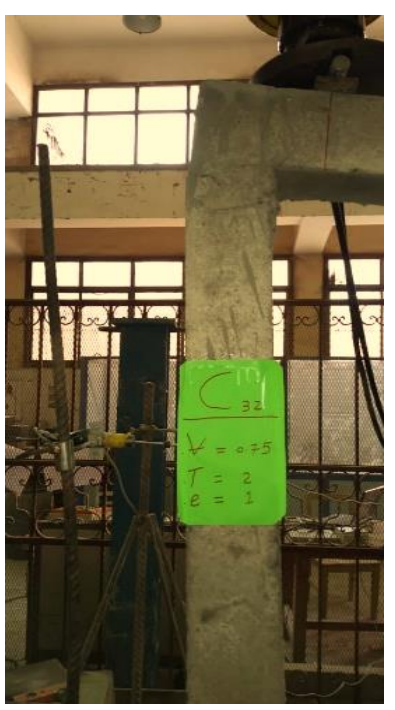

g) Specimen C32

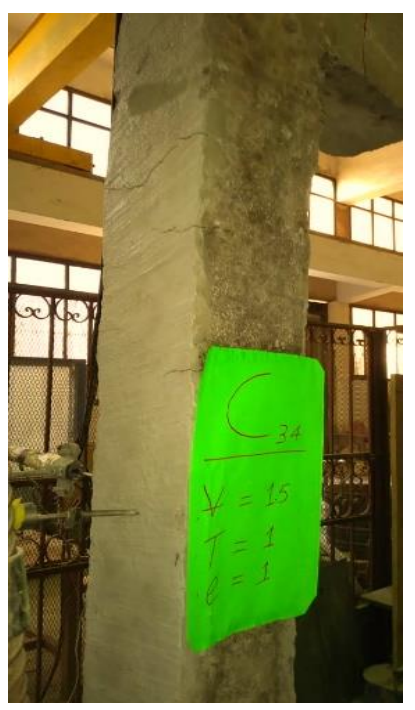

h) Specimen C34

Figure 6 Crack pattern and failure of columns tested under eccentric loads, eccentricity ratio, $\mathrm{e} / \mathrm{t}=1.00$. 


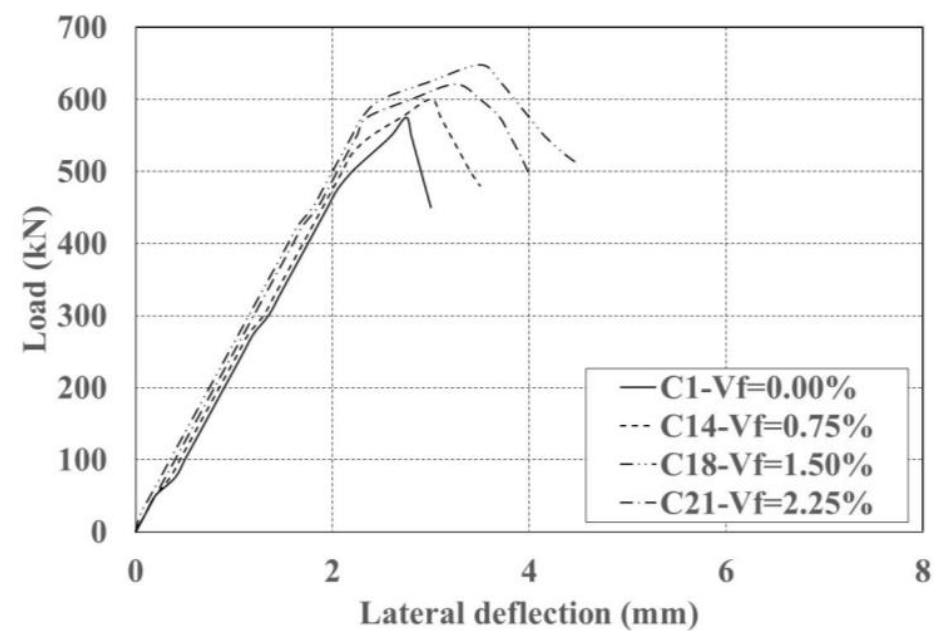

a) At room temperature

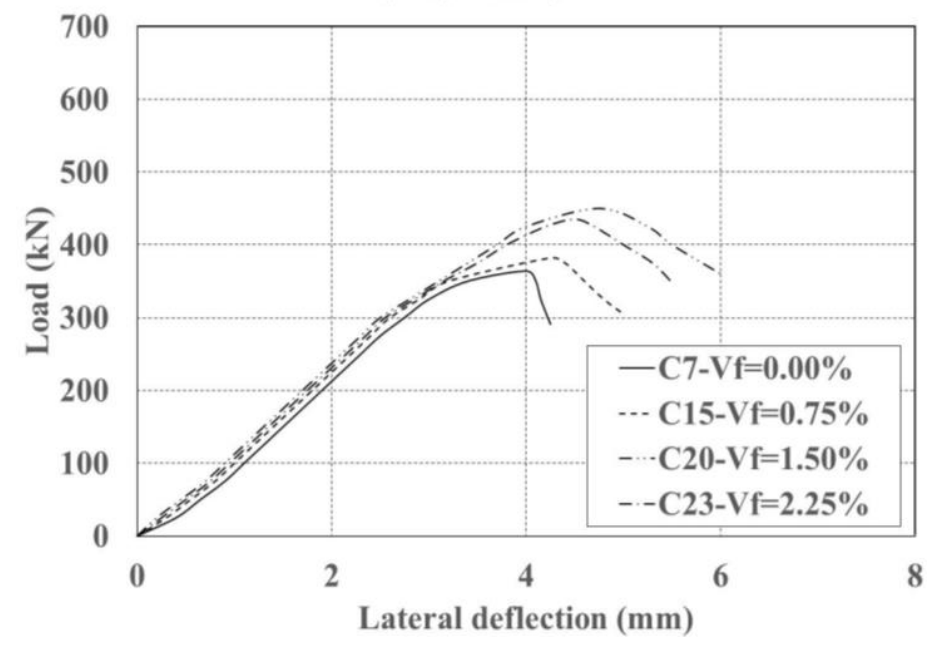

c) After 60 min. temperature exposure

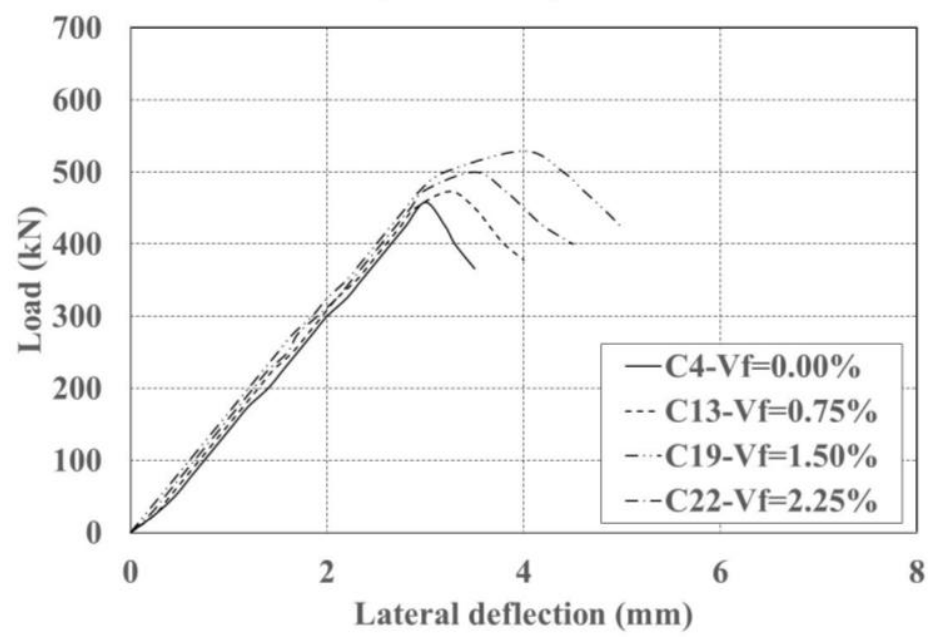

b) After $30 \mathrm{~min}$. temperature exposure

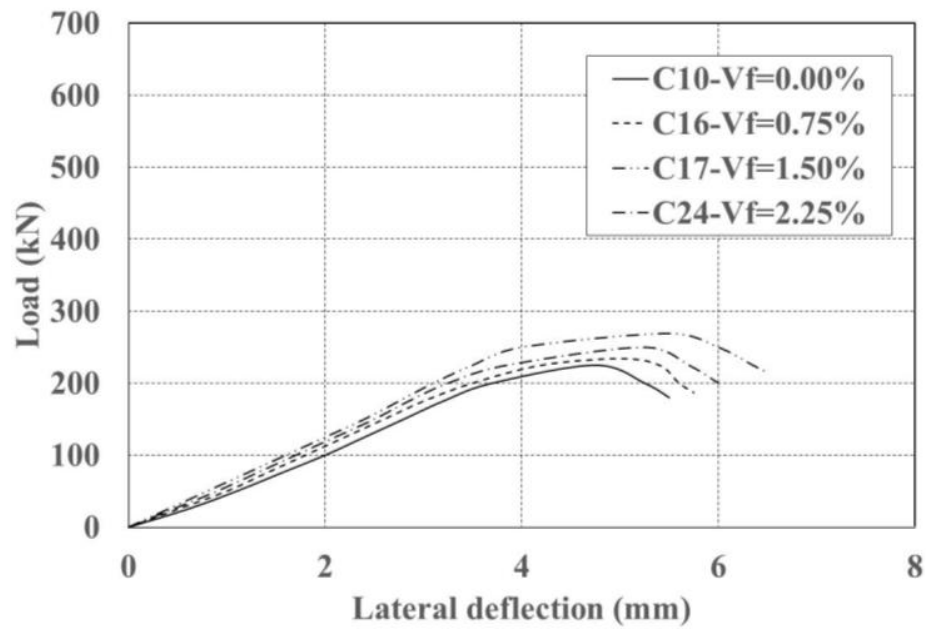

d) After $120 \mathrm{~min}$. temperature exposure

Figure 7 Effect of volumetric ratio of PVA in concrete on the load-mid-height deflection of tested columns at eccentricity ratio, $\mathrm{e} / \mathrm{t}=0.0$ 


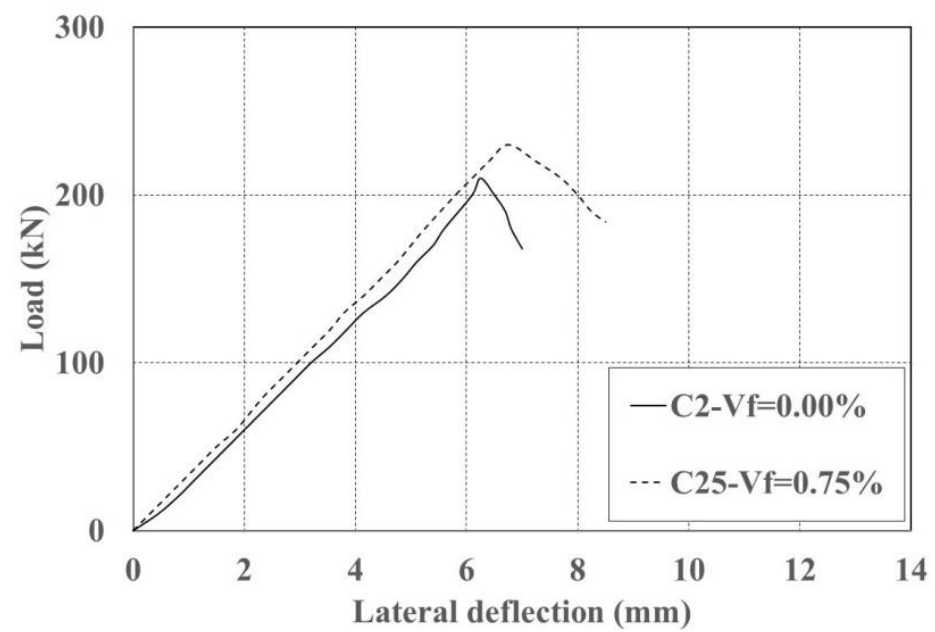

a) At room temperature

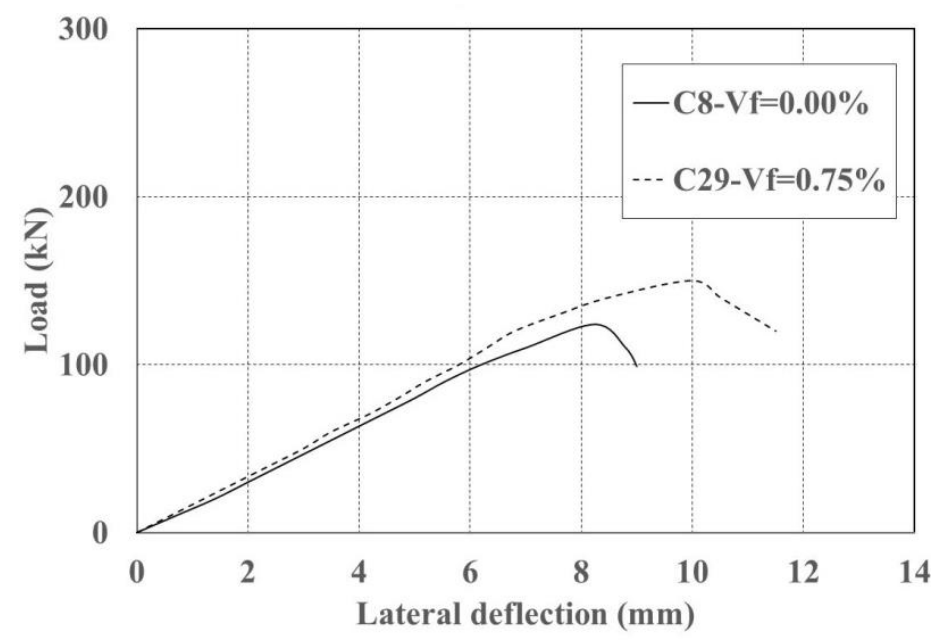

c) After $60 \mathrm{~min}$. temperature exposure

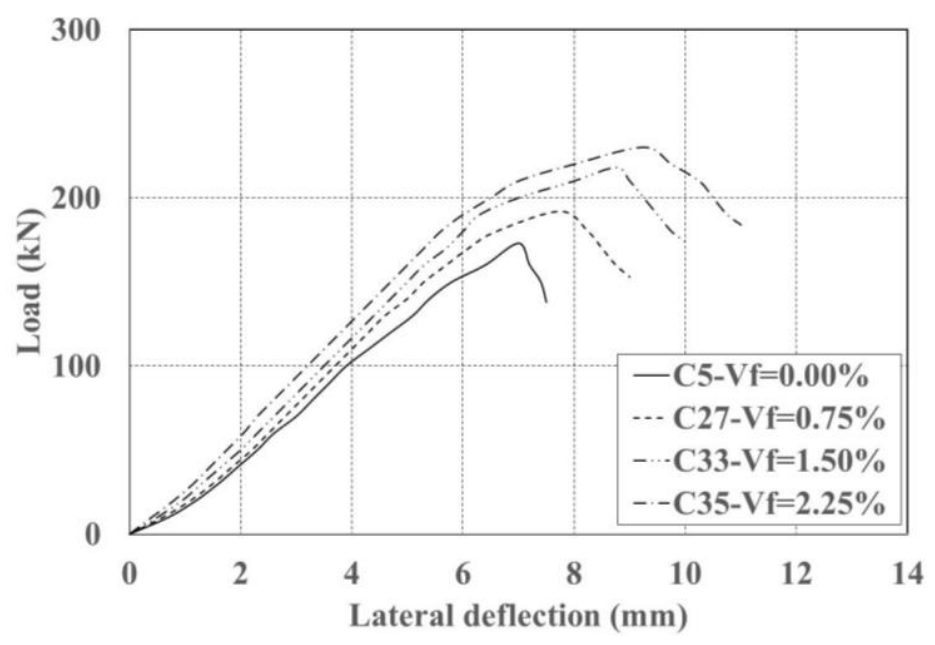

b) After 30 min. temperature exposure

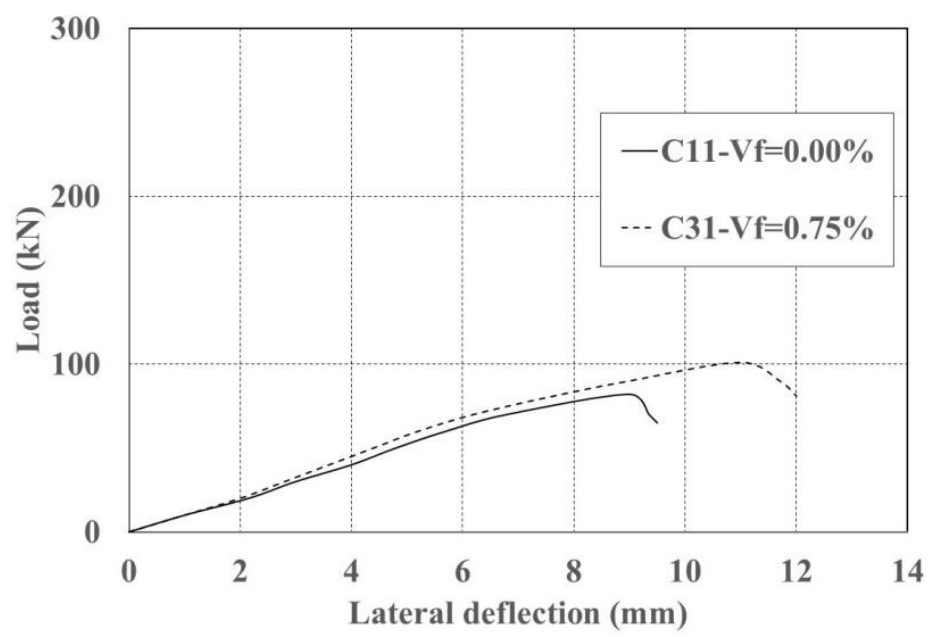

d) After 120 min. temperature exposure

Figure 8 Effect of volumetric ratio of PVA in concrete on load-mid-height deflection of tested columns at eccentricity ratio, $\mathrm{e} / \mathrm{t}=0.50$ 


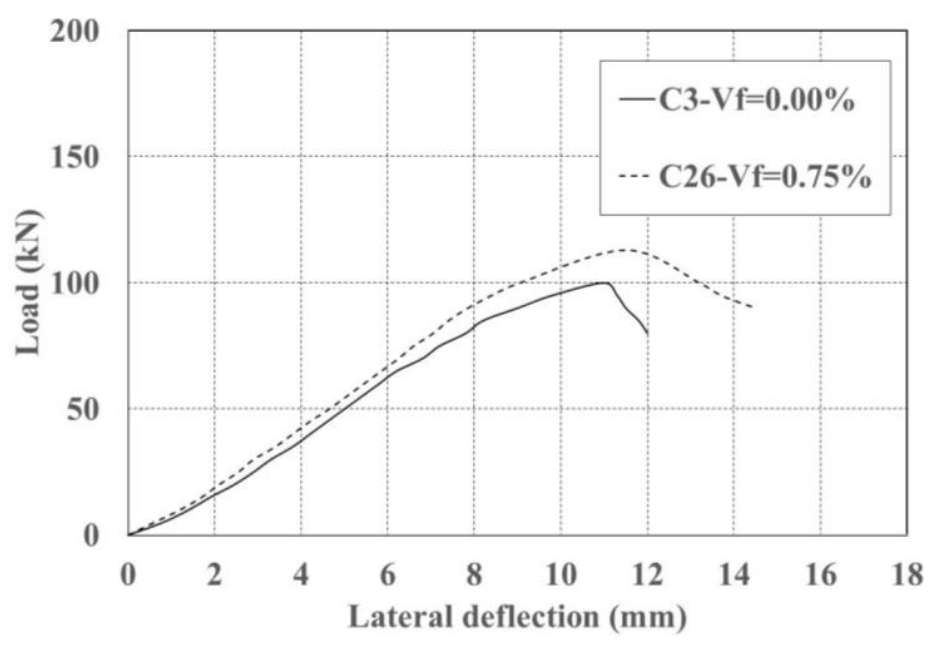

a) At room temperature

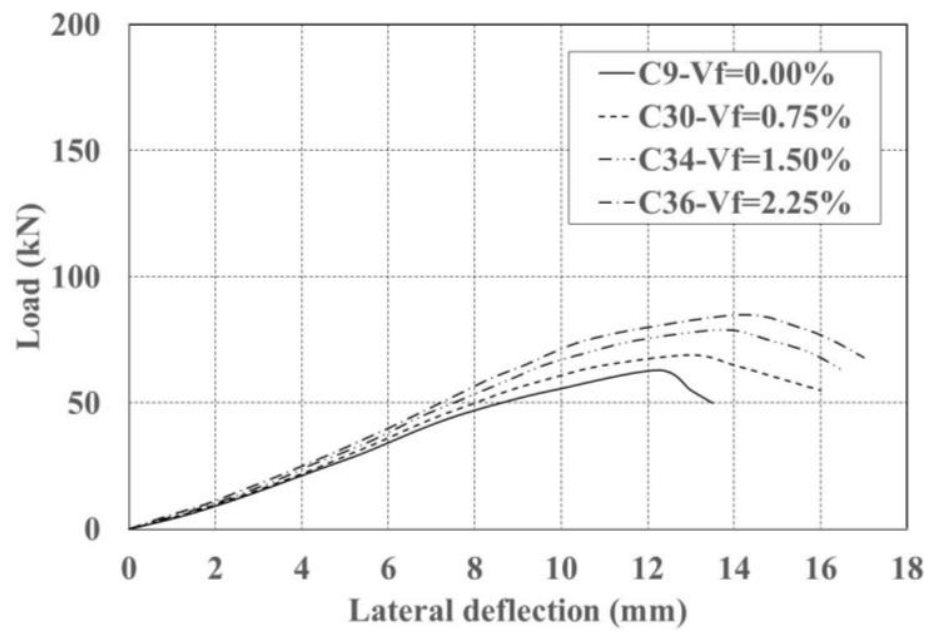

c) After 60 min. temperature exposure

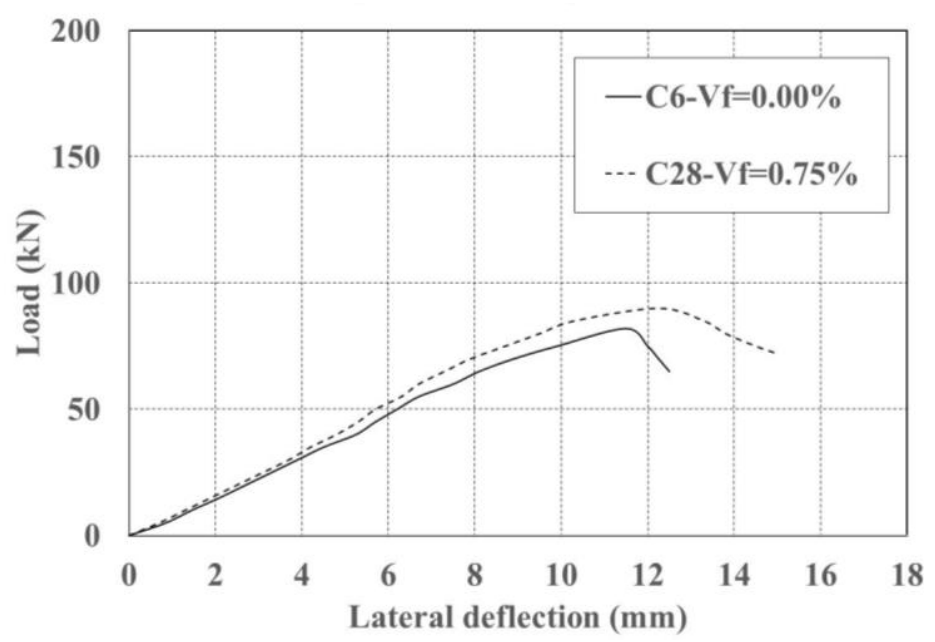

b) After 30 min. temperature exposure

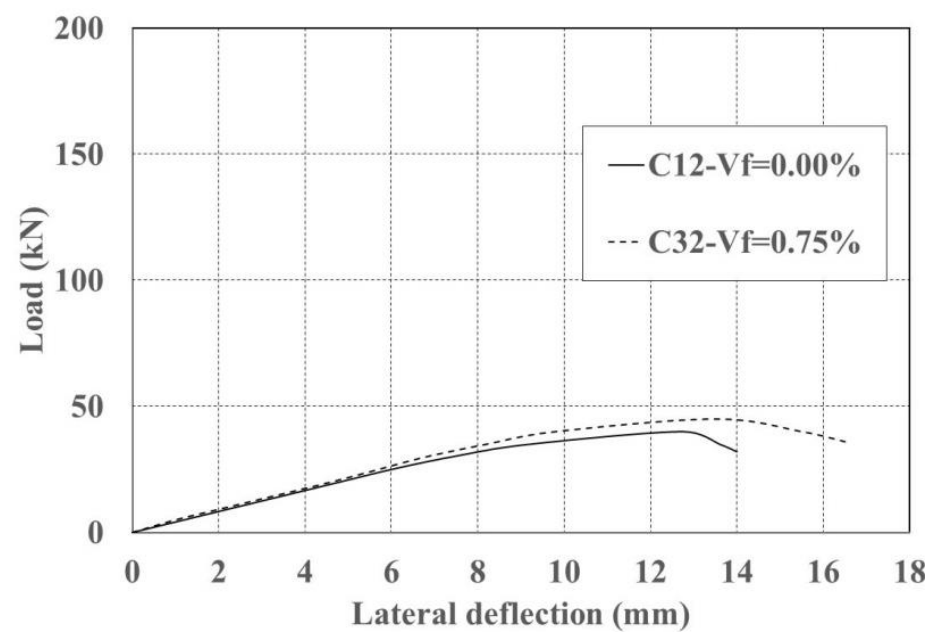

d) After 120 min. temperature exposure

Figure 9 Effect of volumetric ratio of PVA in concrete on Load-mid-height deflection of tested columns at eccentricity ratio, $\mathrm{e} / \mathrm{t}=1.0$ 
Table 1 Properties of the polyvinyl alcohol (PVA).

\begin{tabular}{cccccc}
\hline $\begin{array}{c}\text { Length } \\
(\mathrm{mm})\end{array}$ & $\begin{array}{c}\text { Diameter } \\
(\mathrm{mm})\end{array}$ & $\begin{array}{c}\text { Tensile } \\
\text { strength } \\
(\mathrm{MPa})\end{array}$ & $\begin{array}{c}\text { Young's } \\
\text { Modulus } \\
(\mathrm{GPa})\end{array}$ & $\begin{array}{c}\text { Density } \\
(\mathrm{g} / \mathrm{cm} 3)\end{array}$ & $\begin{array}{c}\text { Elongation } \\
(\%)\end{array}$ \\
\hline 6 & 0.04 & 1600 & 37 & 1.30 & 6 \\
\hline
\end{tabular}

Table 2 Concrete mix proportions

\begin{tabular}{|c|c|c|c|c|c|c|}
\hline Mix No & $\begin{array}{c}\text { Cement } \\
\mathrm{kg} / \mathrm{m} 3\end{array}$ & $\begin{array}{c}\text { Water } \\
\text { Lit/m3 }\end{array}$ & $\begin{array}{c}\text { Sand } \\
\mathrm{kg} / \mathrm{m} 3\end{array}$ & $\begin{array}{c}\text { Basalt } \\
\mathrm{kg} / \mathrm{m} 3\end{array}$ & $\begin{array}{c}\text { (PVA) } \\
\mathrm{kg} / \mathrm{m} 3\end{array}$ & (PVA) \% \\
\hline 1 & 400 & 192 & 624 & 1122 & 0 & 0 \\
\hline 2 & 400 & 192 & 624 & 1122 & 9.75 & 0.75 \\
\hline 3 & 400 & 192 & 624 & 1122 & 19.50 & 1.50 \\
\hline 4 & 400 & 192 & 624 & 1122 & 29.25 & 2.25 \\
\hline
\end{tabular}

Table 3 Compressive, splitting and flexural strength.

\begin{tabular}{|c|c|c|c|c|}
\hline Mix No. & \% Fibers & $\begin{array}{c}\text { Compressive } \\
\text { strength (MPa) }\end{array}$ & $\begin{array}{c}\text { Splitting tensile } \\
\text { strength (MPa) }\end{array}$ & $\begin{array}{c}\text { Flexural strength } \\
(\mathrm{MPa})\end{array}$ \\
\hline Mix-1 & 0.00 & 30.70 & 3.20 & 5.56 \\
\hline Mix-2 & 0.75 & 32.10 & 4.50 & 7.63 \\
\hline Mix-3 & 1.50 & 34.60 & 6.80 & 9.25 \\
\hline Mix-4 & 2.25 & 32.40 & 6.91 & 9.53 \\
\hline
\end{tabular}


Table 4 Details of test specimens and test results

\begin{tabular}{|c|c|c|c|c|c|c|c|}
\hline Specimen & $\begin{array}{c}\text { Column } \\
\text { dimensions, } \\
\mathrm{mm}\end{array}$ & $\begin{array}{c}\text { Eccentricity } \\
\text { ratio, e/t }\end{array}$ & $\begin{array}{c}\text { Fiber } \\
\text { content } \\
(\mathrm{PVA}) \\
\%\end{array}$ & $\begin{array}{c}\text { Duration } \\
\text { of fire } \\
\text { exposure, } \\
\mathrm{T} \\
\mathrm{min})\end{array}$ & $\begin{array}{c}\text { Ultimate } \\
\text { load, } \\
\mathrm{Pu} \\
\mathrm{kN})\end{array}$ & $\begin{array}{c}\text { Ultimate } \\
\text { deflection, } \\
\text { mm }\end{array}$ & $\begin{array}{c}\text { Energy } \\
\text { absorption, } \\
\mathrm{kN} . \mathrm{mm}\end{array}$ \\
\hline $\mathrm{C} 1$ & $120 \times 120 \times 1000$ & 0.00 & 0.00 & 0 & 575 & 2.75 & 967.50 \\
\hline${ }^{*} \mathrm{C} 2$ & $120 \times 120 \times 1200$ & 0.50 & 0.00 & 0 & 210 & 6.25 & 750.30 \\
\hline${ }^{*} \mathrm{C} 3$ & $120 \times 120 \times 1200$ & 1.00 & 0.00 & 0 & 100 & 11.00 & 680.20 \\
\hline $\mathrm{C} 4$ & $120 \times 120 \times 1000$ & 0.00 & 0.00 & 30 & 458 & 3.00 & 892.60 \\
\hline$* \mathrm{C} 5$ & $120 \times 120 \times 1200$ & 0.50 & 0.00 & 30 & 173 & 7.00 & 676.10 \\
\hline$* \mathrm{C} 6$ & $120 \times 120 \times 1200$ & 1.00 & 0.00 & 30 & 82 & 11.50 & 581.80 \\
\hline $\mathrm{C} 7$ & $120 \times 120 \times 1000$ & 0.00 & 0.00 & 60 & 364 & 4.00 & 760.30 \\
\hline$* \mathrm{C} 8$ & $120 \times 120 \times 1200$ & 0.50 & 0.00 & 60 & 124 & 8.25 & 618.00 \\
\hline$* \mathrm{C} 9$ & $120 \times 120 \times 1200$ & 1.00 & 0.00 & 60 & 63 & 12.25 & 483.30 \\
\hline $\mathrm{C} 10$ & $120 \times 120 \times 1000$ & 0.00 & 0.00 & 120 & 225 & 4.75 & 729.40 \\
\hline$* \mathrm{C} 11$ & $120 \times 120 \times 1200$ & 0.50 & 0.00 & 120 & 82 & 9.00 & 439.40 \\
\hline$* \mathrm{C} 12$ & $120 \times 120 \times 1200$ & 1.00 & 0.00 & 120 & 40 & 12.75 & 350.40 \\
\hline $\mathrm{C} 13$ & $120 \times 120 \times 1000$ & 0.00 & 0.75 & 30 & 473 & 3.25 & 1205.30 \\
\hline $\mathrm{C} 14$ & $120 \times 120 \times 1000$ & 0.00 & 0.75 & 0 & 600 & 3.00 & 1290.30 \\
\hline $\mathrm{C} 15$ & $120 \times 120 \times 1000$ & 0.00 & 0.75 & 60 & 382 & 4.25 & 1020.10 \\
\hline $\mathrm{C} 16$ & $120 \times 120 \times 1000$ & 0.00 & 0.75 & 120 & 234 & 5.00 & 839.40 \\
\hline $\mathrm{C} 17$ & $120 \times 120 \times 1000$ & 0.00 & 1.50 & 120 & 269 & 5.50 & 1141.40 \\
\hline $\mathrm{C} 18$ & $120 \times 120 \times 1000$ & 0.00 & 1.50 & 0 & 648 & 3.50 & 2001.30 \\
\hline $\mathrm{C} 19$ & $120 \times 120 \times 1000$ & 0.00 & 1.50 & 30 & 529 & 4.00 & 1748.80 \\
\hline $\mathrm{C} 20$ & $120 \times 120 \times 1000$ & 0.00 & 1.50 & 60 & 450 & 4.75 & 1450.60 \\
\hline $\mathrm{C} 21$ & $120 \times 120 \times 1000$ & 0.00 & 2.25 & 0 & 621 & 3.25 & 1653.40 \\
\hline $\mathrm{C} 22$ & $120 \times 120 \times 1000$ & 0.00 & 2.25 & 30 & 500 & 3.50 & 1496.00 \\
\hline $\mathrm{C} 23$ & $120 \times 120 \times 1000$ & 0.00 & 2.25 & 60 & 435 & 4.50 & 1200.00 \\
\hline $\mathrm{C} 24$ & $120 \times 120 \times 1000$ & 0.00 & 2.25 & 120 & 250 & 5.25 & 945.00 \\
\hline
\end{tabular}




\begin{tabular}{|c|c|c|c|c|c|c|c|}
\hline$* \mathrm{C} 25$ & $120 \times 120 \times 1200$ & 0.50 & 0.75 & 0 & 230 & 6.75 & 1140.70 \\
\hline${ }^{*} \mathrm{C} 26$ & $120 \times 120 \times 1200$ & 1.00 & 0.75 & 0 & 113 & 11.50 & 1012.10 \\
\hline${ }^{*} \mathrm{C} 27$ & $120 \times 120 \times 1200$ & 0.50 & 0.75 & 30 & 192 & 7.75 & 1008.50 \\
\hline$* \mathrm{C} 28$ & $120 \times 120 \times 1200$ & 1.00 & 0.75 & 30 & 90 & 12.25 & 846.50 \\
\hline$* \mathrm{C} 29$ & $120 \times 120 \times 1200$ & 0.50 & 0.75 & 60 & 150 & 10.00 & 900.10 \\
\hline$* \mathrm{C} 30$ & $120 \times 120 \times 1200$ & 1.00 & 0.75 & 60 & 69 & 13.00 & 681.00 \\
\hline$* \mathrm{C} 31$ & $120 \times 120 \times 1200$ & 0.50 & 0.75 & 120 & 101 & 11.00 & 721.50 \\
\hline$* \mathrm{C} 32$ & $120 \times 120 \times 1200$ & 1.00 & 0.75 & 120 & 45 & 13.50 & 488.20 \\
\hline$* \mathrm{C} 33$ & $120 \times 120 \times 1200$ & 0.50 & 1.50 & 30 & 218 & 8.75 & 1312.50 \\
\hline$* \mathrm{C} 34$ & $120 \times 120 \times 1200$ & 1.00 & 1.50 & 60 & 79 & 13.75 & 797.00 \\
\hline$* \mathrm{C} 35$ & $120 \times 120 \times 1200$ & 0.50 & 2.25 & 30 & 230 & 9.25 & 1413.30 \\
\hline$* \mathrm{C} 36$ & $120 \times 120 \times 1200$ & 1.00 & 2.25 & 60 & 85 & 14.25 & 890.00 \\
\hline
\end{tabular}

*C-Shaped specimens (see Figure 1b) 


\section{Highlights}

- Columns with PVA fibers had better performance than their companions without fibers

- Inclusion of PVA fibers increased the temperature resistance of studied columns

- Heat duration and PVA fibers content affect the rapid deterioration of columns

- Inclusion of 1.5\% PVA enhanced ductility and energy absorption for heated columns 